Check for updates

Cite this: RSC Adv., 2017, 7, 28763

Received 6th March 2017 Accepted 24th May 2017 DOI: $10.1039 / \mathrm{c} 7 \mathrm{raO} 2750 \mathrm{~h}$

rsc.li/rsc-advances

\section{Magnetic, structural and surface properties of functionalized maghemite nanoparticles for copper and lead adsorption $\uparrow$}

\author{
Juan A. Ramos Guivar, (D) *a Elahe Sadrollahi, ${ }^{\text {b }}$ Dirk Menzel, ${ }^{b}$ Edson G. Ramos \\ Fernandes, ${ }^{c}$ Elvis O. López, ${ }^{d}$ Marco Morales Torres, ${ }^{e}$ Jesús M. Arsuaga, ${ }^{f}$ \\ Amaya Arencibia ${ }^{f}$ and F. Jochen Litterst ${ }^{\text {bd }}$
}

\begin{abstract}
In this study, magnetic nanocomposites were developed and used as adsorbents for lead and copper from aqueous media. Structural, surface, magnetic and textural properties of functionalized maghemite nanoparticles synthesized by alkaline co-precipitation were studied. The surfaces of the iron oxide nanoparticles (Nps) were modified with different chemical agents such as fatty and amino acids, silica $\left(\mathrm{SiO}_{2}\right)$, mesoporous silica (SBA-15), hydroxyapatite, multiwall carbon nanotubes (MWCNTs) and ethylenediaminetetraacetic acid (EDTA), obtaining NPs with mean particle sizes ranging from 7 to $16 \mathrm{~nm}$ according to Rietveld refinement and TEM images analysis. The physicochemical surface properties of the functionalized materials were studied via zeta potential ( $\zeta$ ) and Fourier transform infrared (FTIR) spectroscopy. Mössbauer spectroscopy (MS) as a function of temperature and DC magnetometry were used to study the magnetic properties. The superparamagnetic relaxation was studied by MS. The resolved spectra at $20 \mathrm{~K}$ confirm the presence of nanomaghemite phase. Besides, the saturation magnetization varies from 12 to $62 \mathrm{emu} \mathrm{g}^{-1}$. A nitrogen adsorption-desorption technique was used to determine the specific surface area and to study the porous structure. The functionalized $\gamma-\mathrm{Fe}_{2} \mathrm{O}_{3} \mathrm{Nps}$ exhibited a Brunauer-Emmett-Teller (BET) specific surface area ranging from 74 to $214 \mathrm{~m}^{2} \mathrm{~g}^{-1}$ and revealed remarkable uptake capacities to remove $\mathrm{Cu}(॥)$ and $\mathrm{Pb}(॥)$ species from aqueous solutions.
\end{abstract}

\section{Introduction}

Copper and lead are relevant contaminants in the environment, which can affect significantly human health. ${ }^{\mathbf{1 - 3}}$ Some mental illnesses caused by constant uptake via ingestion, inhalation and dermal contact of these metals at high concentrations are neurodegenerative disorders, Alzheimer type II astrocytosis, Parkinsonism and ataxia., ${ }^{\mathbf{1} 2}$ Therefore, the presence in water of these metals, due to natural processes and human activities, should be avoided. Many efforts have been developed to find an adequate process for the removal of $\mathrm{Cu}$ (II) and $\mathrm{Pb}$ (II), such as chemical precipitation, ion-exchange processes, membrane

${ }^{a}$ Faculty of Physical Sciences, National University of San Marcos, P. O. Box 14-0149, Lima 14, Peru.E-mail: aguivar@gmail.com; juan.ramos5@unmsm

${ }^{b}$ Institut für Physik der Kondensierten Materie, Technische Universität Braunschweig, 38110 Braunschweig, Germany

'Instituto de Ciência e Tecnologia, Universidade Federal de São Paulo, Av. Cesare Mansueto Giulio Lattes, 1201, 12247-014, São José dos Campos, SP, Brazil

${ }^{d}$ Brazilian Center for Research in Physics (CBPF), Rio de Janeiro, RJ 22290-180, Brazil ${ }^{e}$ Departamento de Física Teórica e Experimental, UFRN, Natal, RN 59078-970, Brazil ${ }^{f}$ Environmental and Chemical Engineering Group, Universidad Rey Juan Carlos, C/ Tulipán s/n, Móstoles, Madrid, Spain

$\dagger$ Electronic supplementary information (ESI) available. See DOI: 10.1039/c7ra02750h filtration, electrodialysis, electrochemical treatments and adsorption. ${ }^{4,5}$ The last one is recommended as an effective and reliable method due to its reproducibility, low-cost and simplicity. Thus, in this worrying context some metal-sorbent prototypes based on magnetic nanoparticles (Nps) are being developed for environmental purposes, for instance in the removal of organic and inorganic metals pollutants from contaminated water. ${ }^{2,3}$ Ali summarized some of these current adsorbents proposed for water treatment, some of them are FeOOH-coated maghemite, gum arabic modified iron oxide magnetic Nps (13-67 nm), zero-valent iron (10-30 nm) among others. $^{2}$ These modified magnetic nanoadsorbents have high capability for metal traces adsorption, low toxic effects and are easy to separate magnetically. ${ }^{2,3}$ Among a wide variety of nanoparticles, pure iron oxide Nps exhibit adsorption affinity to metallic traces. ${ }^{2}$ Besides, their adsorption capabilities can be improved by functionalization with other inorganic and organic materials containing functional groups that help for the uptake of these metals. ${ }^{2}$ In addition, the coating prevents the Nps from flocculation and agglomeration caused by dipole-dipole and van der Waals force interactions, thus being presented as a very important group of adsorbents for metal removal. However, some conditions like colloidal stability, critical particle size and pore diameter, saturation magnetization, specific surface area, 
etc., should be thoroughly studied before their use in environmental applications. ${ }^{2,6}$

Several techniques are reported in the abundant literature to synthesize magnetic Nps. ${ }^{7}$ For example, thermal decomposition is used to produce mono-disperse Nps with very high narrow particle size distribution and variety of sizes $(5-20 \mathrm{~nm}){ }^{7}$ The synthesis is carried out in organic environment where solvents with high melting point and expensive surfactants are used as dispersive medium to produce hydrophobic Nps with attractive and defined morphologies. ${ }^{7,8}$ But, very cautious laboratory conditions and higher temperatures are also employed and subsequent surface modifications should be followed to make the Nps hydrophilic., ${ }^{910}$ In addition, the resultant mass is less than $1 \mathrm{~g}$, making this method inadequate and expensive to be used for environmental applications. ${ }^{10}$ However, the coprecipitation method seems to be the most appropriate method to give scalability and future industrial applications to the iron oxide Nps, this method was firstly proposed by Kang et al. without the presence of surfactants. ${ }^{11}$ It consists in the homogenous nucleation and growth of Nps using iron precursors that precipitate in alkaline medium. The method yields particles with a wide particle size distribution where the mean diameters vary between $6-15 \mathrm{~nm}$, and the subsequent functionalization with other agents can be achieved. ${ }^{7}$

In this paper, the synthesis and characterization of functionalized maghemite $\left(\gamma-\mathrm{Fe}_{2} \mathrm{O}_{3}\right)$ Nps with different inorganic and organic agents were studied, achieving a detailed properties description including structural, surface and magnetic characterization. The characterization of the textural properties (specific surface area, pore diameter) of our maghemite nanoparticles functionalized with different agents was also carried out. Their application as magnetic nanoadsorbents were tested for $\mathrm{Cu}$ (II) and $\mathrm{Pb}(\mathrm{II})$ heavy metals removal from aqueous solution.

\section{Experimental}

\section{Materials}

Iron(II) sulphate heptahydrate $\left(\mathrm{FeSO}_{4} \cdot 7 \mathrm{H}_{2} \mathrm{O}\right)$, iron(III) chloride anhydrous $\left(\mathrm{FeCl}_{3}\right)$, iron(III) chloride hexahydrate $\left(\mathrm{FeCl}_{3} \cdot 6 \mathrm{H}_{2} \mathrm{O}\right)$, iron(II) chloride tetrahydrate $\left(\mathrm{FeCl}_{2} \cdot 4 \mathrm{H}_{2} \mathrm{O}\right)$, ammonium hydroxide $\left(\mathrm{NH}_{4} \mathrm{OH}, 28-30 \%\right)$, tetraethyl orthosilicate (TEOS), lauric acid (LA), oleic acid (OA), copper(II) nitrate trihydrate extrapure $\left(\mathrm{Cu}\left(\mathrm{NO}_{3}\right)_{2} \cdot 3 \mathrm{H}_{2} \mathrm{O}\right)$ and lead(II) nitrate $\left(\mathrm{Pb}\left(\mathrm{NO}_{3}\right)_{2}\right)$; were of analytical grade and obtained from Sigma Aldrich and used without further purification. L-Arginine (L-arg) monohydrochloride (98\%) was purchased from Alfa Aesar. Multi Walled Carbon Nanotubes (MWCNTs) were obtained from Cheaptubes with outer diameter: 20-30 nm, inner diameter: $5-10 \mathrm{~nm}$, ash: $<1.5 \mathrm{wt} \%$, purity: $>95$ wt $\%$, length: $10-30 \mu \mathrm{m}$ and BET specific surface area: $110 \mathrm{~m}^{2} \mathrm{~g}^{-1}$. Ultrapure water (resistivity of $18.3 \mathrm{M} \Omega \mathrm{cm}$ ) was obtained from a Millipore Milli-Q Water System (Millipore Inc.), and was used for rinsing and to prepare all aqueous solutions.

\section{Adsorbents synthesis}

Synthesis of $\gamma-\mathrm{Fe}_{2} \mathrm{O}_{3} @ \mathrm{SiO}_{2} \mathrm{Nps}$ and $\gamma-\mathrm{Fe}_{2} \mathrm{O}_{3} \mathrm{Nps}$ deposited onto SBA-15. The $\gamma-\mathrm{Fe}_{2} \mathrm{O}_{3}$ Nps were synthesized according to the previously reported procedure by the co-precipitation method keeping the stoichiometric ratio between iron species, $\mathrm{Fe}^{2+} / \mathrm{Fe}^{3+}$ $\approx 0.5$ to prepare the sample labeled as $\gamma-\mathrm{Fe}_{2} \mathrm{O}_{3}-1{ }^{12}$ Briefly, magnetite $\left(\mathrm{Fe}_{3} \mathrm{O}_{4}\right)$ Nps were synthesized using $5.2 \mathrm{~g}$ of $\mathrm{FeCl}_{3}$ and $2.0 \mathrm{~g}$ of $\mathrm{FeCl}_{2}$ that were dissolved in water under stirring. The resulting solution was added in $250 \mathrm{~mL}$ of $1.5 \mathrm{M} \mathrm{NaOH}$ solution, and kept under stirring. The last step produced a black precipitate $(\mathrm{pH}=12)$. Then, the quick oxidation of $\mathrm{Fe}_{3} \mathrm{O}_{4}$ into $\gamma$ $\mathrm{Fe}_{2} \mathrm{O}_{3}$ was carried out by adjusting the $\mathrm{pH}$ of $\mathrm{Fe}_{3} \mathrm{O}_{4}$ to 3.5 with hydrochloric acid at about $80^{\circ} \mathrm{C}$ for $30 \mathrm{~min}$ and under magnetic stirring. This sample was used as support to obtain the $\gamma-\mathrm{Fe}_{2}-$ $\mathrm{O}_{3} @ \mathrm{SiO}_{2} \mathrm{Nps}$, the synthesis procedure is as follows: $0.101 \mathrm{~g}$ of $\gamma$ $\mathrm{Fe}_{2} \mathrm{O}_{3}-1 \mathrm{Nps}$ were re-suspended in $48 \mathrm{~mL}$ of ethanol and $12 \mathrm{~mL}$ of ultrapure water under stirring at room temperature, and under sonication for $30 \mathrm{~min}$, the $\mathrm{pH}$ solution value was adjusted to 11 with ammonium hydroxide $\left(\mathrm{NH}_{4} \mathrm{OH}, 28-30 \%\right)$. Then, $1 \mathrm{~mL}$ of TEOS was added to the brown dispersion and kept under moderate stirring for $14 \mathrm{~h}$ at $50{ }^{\circ} \mathrm{C}$. The $\gamma-\mathrm{Fe}_{2} \mathrm{O}_{3} @ \mathrm{SiO}_{2} \mathrm{Nps}$ were decanted using a magnet and washed several times with ultrapure water. Then, the sample was dried at $80^{\circ} \mathrm{C}$ for $12 \mathrm{~h}$.

To deposit $\gamma-\mathrm{Fe}_{2} \mathrm{O}_{3}$ Nps onto the SBA-15 pores, mesoporous SBA-15 synthesized by the previously reported method was used. ${ }^{13}$ Briefly, an amount of $1.5 \mathrm{~g}$ of pure SBA- 15 was dispersed in water by sonication for $30 \mathrm{~min}$, then an aqueous solution containing iron precursors at molar ratio $\mathrm{Fe}^{2+} / \mathrm{Fe}^{3+} \approx 0.5 \mathrm{~mol}$ mol $^{-1}$ was added. ${ }^{12}$ Then, the same procedure described above to obtain $\gamma-\mathrm{Fe}_{2} \mathrm{O}_{3}$ Nps was followed. The obtained sample was labeled as $\gamma-\mathrm{Fe}_{2} \mathrm{O}_{3}$-SBA15.

Synthesis of $\gamma-\mathrm{Fe}_{2} \mathrm{O}_{3}$ with fatty acids. The co-precipitation method was also used to obtain $\gamma-\mathrm{Fe}_{2} \mathrm{O}_{3}$ Nps but the basic agent was changed. In this case, a $28-30 \% \mathrm{NH}_{4} \mathrm{OH}$ solution was slowly dropped into a $30 \mathrm{~mL}$ of an aqueous solution containing $\mathrm{FeCl}_{3} \cdot 6 \mathrm{H}_{2} \mathrm{O}$ and $\mathrm{FeCl}_{2} \cdot 4 \mathrm{H}_{2} \mathrm{O}$ under vigorous stirring. The solution was heated to $80{ }^{\circ} \mathrm{C}$ for $30 \mathrm{~min}$, and the medium $\mathrm{pH}$ was maintained at 12 by addition of ammonia. The magnetic dispersion was then stirred for $1 \mathrm{~h}$ at $80{ }^{\circ} \mathrm{C}$ with $\mathrm{N}_{2}$ flux bubbled throughout the reaction. Subsequently, the resultant ultrafine magnetic particles were washed several times with ultrapure water using a magnet, and then redispersed into an aqueous suspension $(50 \mathrm{~mL}, \mathrm{pH}=7)$. These Nps were labeled as $\gamma-\mathrm{Fe}_{2} \mathrm{O}_{3}-2$.

The syntheses of $\gamma-\mathrm{Fe}_{2} \mathrm{O}_{3}-2$ Nps functionalized with oleic acid, OA, and lauric acid, LA, (labeled as $\gamma-\mathrm{Fe}_{2} \mathrm{O}_{3} @ \mathrm{OA}$ and $\gamma$ $\mathrm{Fe}_{2} \mathrm{O}_{3} @ L A$, respectively) were carried out by dispersing a certain amount of the $\gamma-\mathrm{Fe}_{2} \mathrm{O}_{3}-2$ Nps into OA and LA solutions. This mixture was stirred for $30 \mathrm{~min}$ at $80{ }^{\circ} \mathrm{C}$. The final dispersions were filtered and washed several times up to neutral $\mathrm{pH}$. Then, it was dried at $60{ }^{\circ} \mathrm{C}$ for $12 \mathrm{~h}$.

Synthesis of $\boldsymbol{\gamma}-\mathrm{Fe}_{2} \mathrm{O}_{3} @ \mathrm{~L}$-arg. The synthesis was performed by mixing $\mathrm{FeCl}_{2} \cdot 4 \mathrm{H}_{2} \mathrm{O}, \mathrm{FeCl}_{3} \cdot 6 \mathrm{H}_{2} \mathrm{O}$ and $\mathrm{L}$-arg in a molar ratio of $1: 2: 0.5$, respectively. This solution was stirred and heated up to reach $80{ }^{\circ} \mathrm{C}$ in a $\mathrm{N}_{2}$ reflux system. Then, ammonium hydroxide $\left(\mathrm{NH}_{4} \mathrm{OH}\right)$ was added to the solution and the mixture was maintained under stirring for $60 \mathrm{~min}$. The sample was washed several times to remove the excess of free amino acid molecules and to reduce $\mathrm{pH}$ to 7 . The final solution was filtered and washed several times till $\mathrm{pH}=7$. Then, it was dried at $60^{\circ} \mathrm{C}$ for $12 \mathrm{~h}$. 
Synthesis of $\gamma-\mathrm{Fe}_{2} \mathrm{O}_{3} @ M W C N T s$ nanohybrid. To obtain the $\gamma-\mathrm{Fe}_{2} \mathrm{O}_{3} @ M W C N T$ nanohybrid a previous activation step of Multi Walled Carbon Nanotubes was carried out to incorporate the $\mathrm{COOH}$ groups by using concentrated nitric acid. ${ }^{14} 1 \mathrm{~g}$ of MWCNTs was added to a flask containing $10 \mathrm{~mL}$ of $\mathrm{HNO}_{3}$ solution $(3 \mathrm{M})$. The dispersion was heated to $60{ }^{\circ} \mathrm{C}$ and kept under stirring for $24 \mathrm{~h}$. Then it was cooled to RT, filtered and washed several times with ultrapure water till $\mathrm{pH}=7$ was reached. The powder was dried during $12 \mathrm{~h}$ at $100{ }^{\circ} \mathrm{C}$. This sample was labeled as oxidized (o)-MWCNTs.

The Nps were deposited onto the o-MWCNTs by the deposition-precipitation method using iron precursors solution with molar ratio $\mathrm{Fe}^{2+} / \mathrm{Fe}^{3+} \approx 0.5$ in alkaline conditions. ${ }^{12}$ Briefly, $200 \mathrm{mg}$ of o-MWCNTs were dispersed in ultrapure water for $15 \mathrm{~min}$ and then kept in air at $80{ }^{\circ} \mathrm{C}$ under vigorous stirring. After that, $\mathrm{FeCl}_{3}(1.24 \mathrm{mmol})$ and $\mathrm{FeSO}_{4} \cdot 7 \mathrm{H}_{2} \mathrm{O}(0.62$ mmol) were added to the solution containing o-MWCNTs. Immediately, a solution of $\mathrm{NaOH}(1.5 \mathrm{M})$ was added dropwise till the $\mathrm{pH}$ reached 12 . The mixture was left to react for a period of $2 \mathrm{~h}$ through the expected following chemical reaction: ${ }^{15}$

$$
\begin{gathered}
\mathrm{Fe}^{2+}+2 \mathrm{Fe}^{3+}+8 \mathrm{OH}^{-}+\text {o-MWCNTs } \mathrm{Fe}_{3} \mathrm{O}_{4} / \mathrm{o}-\mathrm{MWCNTs}+ \\
4 \mathrm{H}_{2} \mathrm{O}
\end{gathered}
$$

The obtained dispersion was cooled to RT, magnetically separated and then filtered using a $2 \mu \mathrm{m}$ membrane filter to remove free magnetic $\mathrm{Nps}$, the obtained solid was washed several times with ultrapure water till the $\mathrm{pH}$ was 7 . The sample was dried at $80{ }^{\circ} \mathrm{C}$ for $12 \mathrm{~h}$ and the material was labeled as $\gamma$ $\mathrm{Fe}_{2} \mathrm{O}_{3} @ M W C N T s$.

Synthesis of $\gamma-\mathrm{Fe}_{2} \mathrm{O}_{3} @ H A p$ and NPEDTA. The synthesis and characterization of these compounds are described in our previous papers. ${ }^{16,17}$ Briefly, $5.41 \mathrm{~g}$ of $\mathrm{FeCl}_{3} \cdot 6 \mathrm{H}_{2} \mathrm{O}$ and $1.99 \mathrm{~g}$ of $\mathrm{FeCl}_{2} \cdot 4 \mathrm{H}_{2} \mathrm{O}$ were dispersed in $50 \mathrm{~mL}$ of water. Then, $1.14 \mathrm{~g}$ of EDTA was added to the mixture. The reaction process was kept under magnetic stirring at $70{ }^{\circ} \mathrm{C}$ for $30 \mathrm{~min}$ upon the addition of $24 \mathrm{~mL}$ of $\mathrm{NH}_{4} \mathrm{OH}$ to adjust the solution $\mathrm{pH}$ to 12. After the black precipitate formation the particles were washed several times and separated by magnetic decantation. Finally, the Nps were dried at $60{ }^{\circ} \mathrm{C}$ for $12 \mathrm{~h}$. The EDTA functionalized $\gamma-\mathrm{Fe}_{2} \mathrm{O}_{3} \mathrm{Nps}$ was labeled as $\gamma-\mathrm{Fe}_{2} \mathrm{O}_{3}$-EDTA1. In the present work, these samples will be further studied in applications related to $\mathrm{Cu}$ (II) and $\mathrm{Pb}$ (II) adsorption.

Heavy metal adsorption experiments. In order to study the metal removal ability of the above samples a set of adsorption experiments was carried out by stirring $25 \mathrm{mg}$ of nanoadsorbent in presence of $45 \mathrm{~mL}$ of a single metal solution at $25{ }^{\circ} \mathrm{C}$. The metals selected were $\mathrm{Cu}(\mathrm{II})$ and $\mathrm{Pb}(\mathrm{II})$. Initial aqueous solution concentrations of these metals were 40 and $50 \mathrm{mg} \mathrm{L}^{-1}$, respectively, and the metal salts used were nitrates in all cases. Adsorbent-solution mixtures were stirred for 7 and $20 \mathrm{~h}$ and then filtered with a conic filter to collect the final solutions. After that, the solid was magnetically decanted from the filtered solution. Metal concentration, both in the initial and final solutions, was determined by inductively coupled plasma atomic emission spectroscopy (ICP-AES). Measurements were performed in a Varian Vista AX spectrometer after calibration with stock solutions in the range of concentration of $0-50 \mathrm{mg} \mathrm{L}^{-1}$. The emission lines used were according to the standard EPA method for analysis of these metals. ${ }^{18}$ Adsorbed heavy metal amount was determined by difference between initial and final metal concentrations in the solution. The adsorbed amount at certain time $t$ is:

$$
q_{t}=\frac{\left(C_{0}-C_{t}\right) V}{m}\left(\mathrm{mg} \mathrm{g}^{-1}\right)
$$

where $q_{t}$ indicates the amount in $\mathrm{mg}$ of adsorbate per gram of adsorbent for a certain time $t . C_{0}$ and $C_{t}$ are the initial and final concentrations ( $\mathrm{mg} \mathrm{L}^{-1}$ ), respectively, $m$ is the adsorbent mass and $V$ is the volume used for the adsorption test.

\section{Characterization}

The X-ray diffraction (XRD) data were obtained by using a diffractometer Philips X-PERT MPD, operating with $\mathrm{CuK}_{\alpha}$ radiation (1.5406 ̊). Powder diffraction patterns were obtained in step scanning mode, $2 \theta=10-80^{\circ}$ with a step of $0.01^{\circ}$ and 4 seconds per step. Rietveld refinement was performed using the software package FullProf. All parameters were refined by the least-squares method. The pseudo-Voigt function modified by Thompson-Cox-Hastings (TCH) was used as peak profile function. For estimating the mean crystallite sizes we took care of corrections due to instrumental broadening that was obtained from corundum $\left(\mathrm{Al}_{2} \mathrm{O}_{3}\right)$ as standard material. The transmission electron micrographs (TEM) were acquired in a JEOL JEM-2000 FX instrument, working at $200 \mathrm{kV}$. Samples were analyzed using a carboncoated copper grid as support of the acetone dispersions of samples prepared by sonication in an ultrasonic bath solution. The $\zeta$-potential values of the dispersion were obtained using a Zeta sizer (Malvern Zs 90, U.K.) equipment. Fourier Transform Infrared spectroscopy (FTIR) (Varian EXCALIBUR SERIES 3100 - UMA 600) measurements were performed in transmission mode with a resolution of $4 \mathrm{~cm}^{-1} \cdot \mathrm{N}_{2}$ adsorption-desorption isotherms at $77 \mathrm{~K}$ were measured by using a Micromeritics Tristar 3000 sorptometer to determine textural properties. Surface area was calculated by using the B.E.T. equation and the pore size distribution was obtained from the adsorption branch by means of the B.J.H. model with cylindrical geometry of the pores; pore volume was taken at $P / P_{0}=0.97$. Measurements by X-ray photoelectron spectroscopy (XPS) at high-energy resolution were carried out in this study. The equipment used was a PHOIBOS 100/150 of the SPECS Company. A polychromatic X-ray from $\mathrm{Al} \mathrm{K} \alpha$ at excitation energy of $1486.6 \mathrm{eV}$ with binding-energy resolution of $0.84 \mathrm{eV}$ was used in these experiments. To calibrate the spectra the adventitious carbon $(\mathrm{C} 1 \mathrm{~s}=284.6 \mathrm{eV}$ ) was used as reference. ${ }^{57} \mathrm{Fe}$ Mössbauer absorption spectra have been collected in transmission geometry using a standard spectrometer with sinusoidal velocity sweep. The powder absorbers were enclosed into nylon containers. Absorber 
thicknesses were chosen equivalent to $c a .0 .1 \mathrm{mg}{ }^{57} \mathrm{Fe}$ per $\mathrm{cm}^{2}$. Absorber temperatures were varied between $20 \mathrm{~K}$ and $300 \mathrm{~K}$ using a variable temperature He-flow cryostat (Cryovac). As $14.4 \mathrm{k} \mathrm{eV} \gamma$-radiation source we used about $40 \mathrm{mCi}$ of ${ }^{57} \mathrm{Co}$ in a Rh matrix kept at RT. Magnetic measurements were performed as a function of temperature (M-T) and magnetic field $(\mathrm{M}-\mathrm{H})$ by using a commercial VSM - Physical Properties Measurement System (PPMS) Dynacool from Quantum Design. The zero field cooling (ZFC) and field cooling (FC) magnetization measurements were recorded in the temperature range from 5 to $300 \mathrm{~K}$ and under a small magnetic field of 80 Oe.

\section{Results and discussion}

The XRD diffractograms for all the synthesized samples are shown in Fig. 1. The comparison of patterns obtained for fatty acids functionalized $\gamma-\mathrm{Fe}_{2} \mathrm{O}_{3}-2 \mathrm{Nps}$ with the original Nps can be observed in Fig. 1a-c. The XRD pattern of $\gamma-\mathrm{Fe}_{2} \mathrm{O}_{3} @ \mathrm{~L}$-arg Nps is shown in Fig. 1d. In general, all diffractograms showed line broadenings related to the nanoscale size of the synthesized

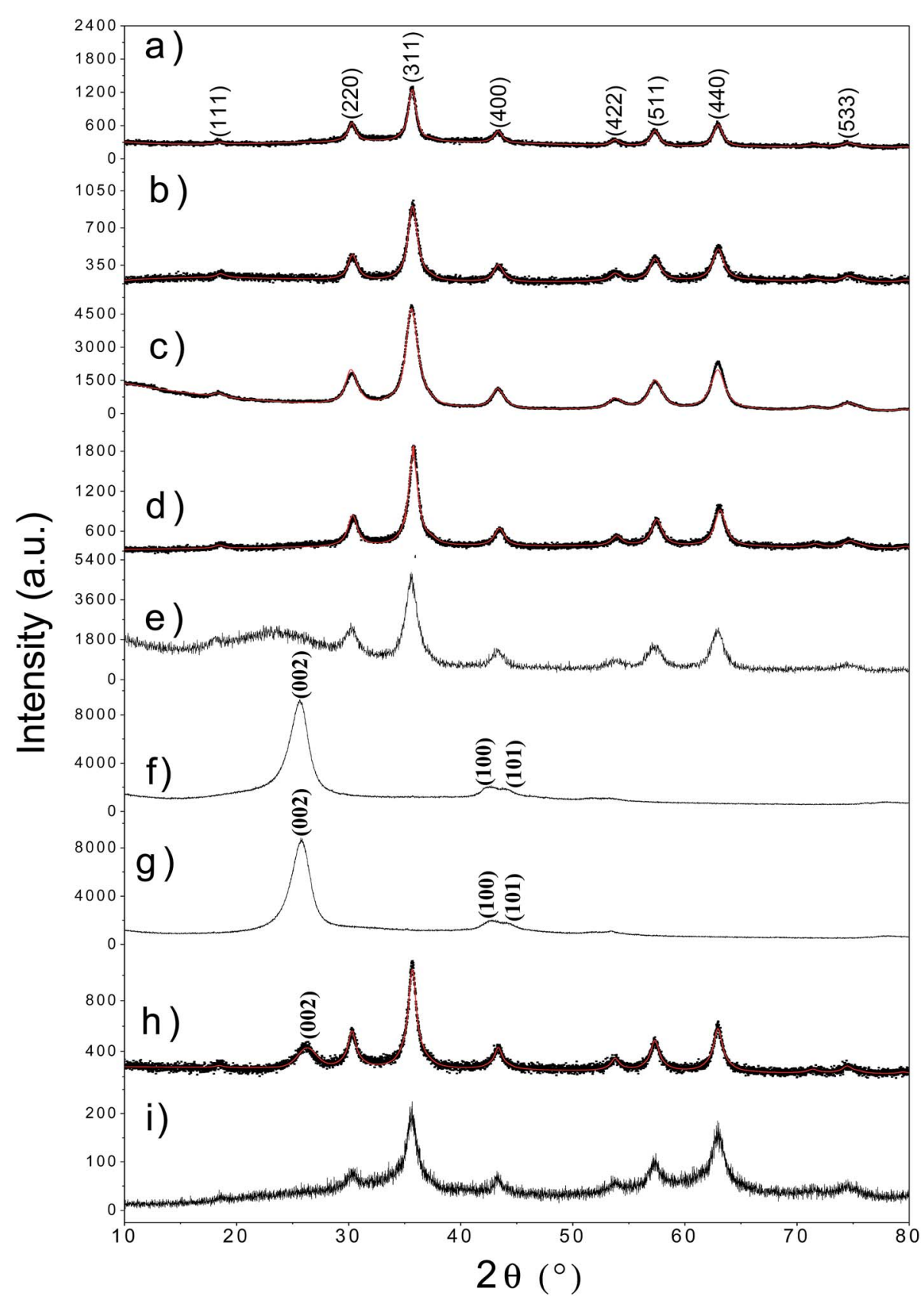

Fig. 1 Rietveld refinement for uncoated maghemite nanoparticles (a) and functionalized with OA (b), LA (c) and L-arg (d). Maghemite nanoparticles coated with $\mathrm{SiO}_{2}$ (e). XRD pattern for untreated MWCNTs (f) and activated with $\mathrm{HNO}_{3}$ (g), $\gamma$-Fe $\mathrm{F}_{2} \mathrm{O}_{3} \mathrm{QMWCNTs}$ hybrid Nps (h) and $\gamma$ $\mathrm{Fe}_{2} \mathrm{O}_{3}$-SBA15 (i). The principal Miller indices for each phase are also indicated. 
Table 1 Crystal parameters and mean nanocrystallites diameter values obtained from Rietveld refinement of XRD patterns and mean nanoparticle diameter obtained from TEM pictures. The $\chi^{2}$ value ranged from 1.3-1.6. (*) It refers to a tetragonal $\gamma-\mathrm{Fe}_{2} \mathrm{O}_{3}$ with red parameters: $a=b=8.322 \AA$ and $c=25.158 \AA$

\begin{tabular}{llll}
\hline Sample & $a(\AA)$ & $d_{\text {XRD }}(\mathrm{nm})$ & $d_{\text {TEM }}(\mathrm{nm})$ \\
\hline$\gamma-\mathrm{Fe}_{2} \mathrm{O}_{3}-1$ (ref. 12) & 8.357 & 6.4 & 6.8 \\
$\gamma-\mathrm{Fe}_{2} \mathrm{O}_{3}-2$ & 8.302 & 7.1 & 9 \\
$\gamma-\mathrm{Fe}_{2} \mathrm{O}_{3} @ \mathrm{SiO}_{2}$ & 8.465 & 10 & 10.4 \\
$\gamma-\mathrm{Fe}_{2} \mathrm{O}_{3}$-SBA15 & 8.345 & 6.2 & $5-9$ \\
$\gamma-\mathrm{Fe}_{2} \mathrm{O}_{3} @$ OA & 8.253 & 5.9 & 6.3 \\
$\gamma-\mathrm{Fe}_{2} \mathrm{O}_{3} @ L A$ & 8.317 & 4.5 & 5.5 \\
$\gamma-\mathrm{Fe}_{2} \mathrm{O}_{3} @ \mathrm{~L}$-arg & 8.330 & 5.9 & 7.7 \\
$\gamma-\mathrm{Fe}_{2} \mathrm{O}_{3} @ H A p$ (ref. 16) & $*$ & 8 & 16 \\
$\gamma-\mathrm{Fe}_{2} \mathrm{O}_{3}$-EDTA1 (ref. 17) & 8.364 & 3 & 4 \\
$\gamma-\mathrm{Fe}_{2} \mathrm{O}_{3} @ M W C N T s$ & 8.359 & 7.3 & 7.5
\end{tabular}

compound. The crystallographic identification was done using the PDF card \# 39-1346 for $\gamma-\mathrm{Fe}_{2} \mathrm{O}_{3} \cdot{ }^{12}$ The main diffraction peak in all patterns associated to $\gamma-\mathrm{Fe}_{2} \mathrm{O}_{3}$ phase is at $2 \theta=35.5^{\circ}$. Other peaks related to pure maghemite phase are observed at $2 \theta$ $=30.2^{\circ}, 43.2^{\circ}, 53.1^{\circ}, 57.1^{\circ}$, and $62.9^{\circ}$ from the (220), (400), (422), (511) and (440) crystallographic planes. ${ }^{12}$ The crystal parameters for all samples obtained from Rietveld refinement are summarized in Table 1. The Rietveld refinement confirmed the presence of inverse spinel cubic structure in the whole set of samples with spatial group $F d \overline{3} m$ and cell parameter ranging from $a=8.25$ to $8.47 \AA$ (Table 1). The diffractogram for sample $\gamma-\mathrm{Fe}_{2} \mathrm{O}_{3} @ \mathrm{SiO}_{2}$ (Fig. 1e) shows a broad peak in the range of $2 \theta=$ $20-30^{\circ}$ due to amorphous silica. Fig. 1f and g show the XRD pattern for un-treated and treated MWCNTs. It can be seen that the acidic treatment has not affected the crystal structure. In that case, the main $(h k l)$ diffractions planes $(002,100,101)$ are
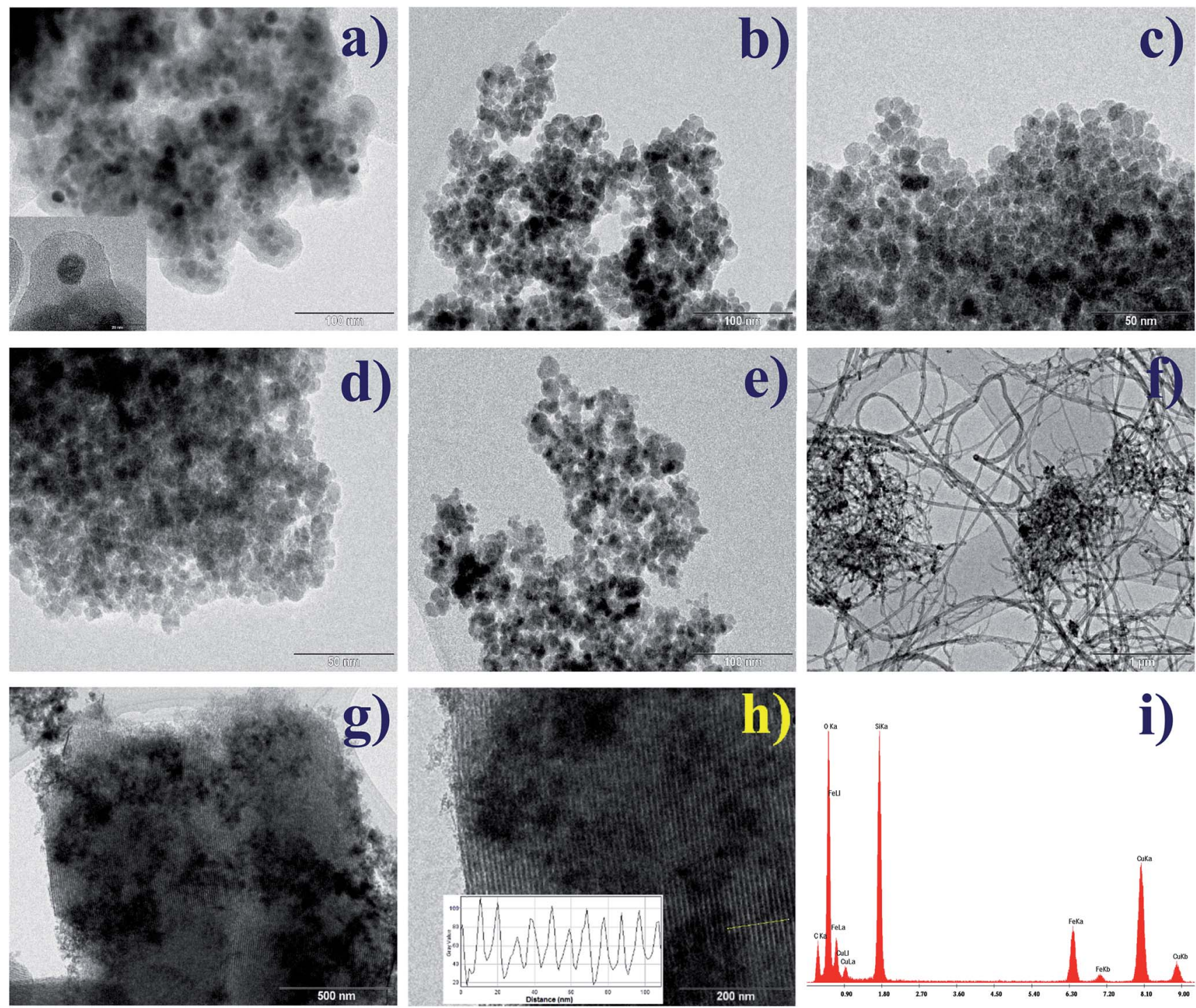

Fig. 2 TEM images for $\gamma-\mathrm{Fe}_{2} \mathrm{O}_{3} \mathrm{CSSiO}_{2}$ (bar length of $100 \mathrm{~nm}$ ) (a) $\gamma-\mathrm{Fe}_{2} \mathrm{O}_{3}-2$ (bar length of $100 \mathrm{~nm}$ ) (b), $\gamma-\mathrm{Fe}_{2} \mathrm{O}_{3} \mathrm{OOA}$ (bar length of $50 \mathrm{~nm}$ ) (c), $\gamma$ $\mathrm{Fe}_{2} \mathrm{O}_{3} \mathrm{QLA}$ (bar length of $50 \mathrm{~nm}$ ) (d), $\gamma-\mathrm{Fe}_{2} \mathrm{O}_{3} \mathrm{aL}-\arg$ (bar length of $100 \mathrm{~nm}$ ) (e), $\gamma-\mathrm{Fe}_{2} \mathrm{O}_{3} \mathrm{aMWCNTs}$ Nps (bar length of $\left.1 \mu \mathrm{m}\right)(\mathrm{f})$ and $\gamma-\mathrm{Fe}_{2} \mathrm{O}_{3}-$ SBA15 (bar length of 500 and $200 \mathrm{~nm}$ ) (g and h). EDX analysis for $\gamma-\mathrm{Fe}_{2} \mathrm{O}_{3}-\mathrm{SBA} 15$ (i). 
Table $2 \zeta$-potential at $\mathrm{pH}=7$, textural and $\mathrm{RT}$ saturation magnetization values for the functionalized $\gamma-\mathrm{Fe}_{2} \mathrm{O}_{3} \mathrm{Nps}$

\begin{tabular}{|c|c|c|c|c|c|}
\hline Sample & $\zeta(\mathrm{mV})$ & $\operatorname{SSA}_{\text {BET }}\left(\mathrm{m}^{2} \mathrm{~g}^{-1}\right)$ & $D_{\mathrm{P}}(\mathrm{nm})$ & $V_{\mathrm{P}}\left(\mathrm{cm}^{3} \mathrm{~g}^{-1}\right)$ & $M_{\mathrm{s}}\left(\mathrm{emu} \mathrm{g}^{-1}\right)$ \\
\hline$\gamma-\mathrm{Fe}_{2} \mathrm{O}_{3}-1$ (ref. 12) & -5 & 129.7 & 8.8 & 0.29 & 62 (ref. 12) \\
\hline$\gamma-\mathrm{Fe}_{2} \mathrm{O}_{3}-2$ & -10 & 88.3 & 17.1 & 0.33 & 59 \\
\hline$\gamma-\mathrm{Fe}_{2} \mathrm{O}_{3}-\mathrm{SBA} 15$ & & 214 & 14.6 & 0.55 & 20 \\
\hline$\gamma-\mathrm{Fe}_{2} \mathrm{O}_{3} @ \mathrm{OA}$ & -40 & 74.8 & 4.7 & 0.09 & 46 \\
\hline$\gamma-\mathrm{Fe}_{2} \mathrm{O}_{3} @ L A$ & -42 & 62.3 & 10 & 0.19 & 44 \\
\hline$\gamma-\mathrm{Fe}_{2} \mathrm{O}_{3}$-EDTA1 (ref. 17) & & 108.6 & 7.8 & 0.25 & 22 \\
\hline$\gamma-\mathrm{Fe}_{2} \mathrm{O}_{3} @ M W C N T s$ & -52 & 129.6 & 13.1 & 0.34 & 37 \\
\hline
\end{tabular}

observed. ${ }^{19}$ After functionalization of MWCNTs with $\gamma-\mathrm{Fe}_{2} \mathrm{O}_{3}$ Nps the diffractogram given in Fig. $1 \mathrm{~h}$ revealed the presence of both phases. The $\gamma-\mathrm{Fe}_{2} \mathrm{O}_{3}$-SBA15 sample only exhibits the peaks of $\gamma-\mathrm{Fe}_{2} \mathrm{O}_{3} \mathrm{Nps}$, in the $2 \theta$ region between $20-25^{\circ}$, the amorphous phase of silica is not observed (see Fig. 1i). The presence of the SBA15 was proven by means of FTIR and TEM measurements.

TEM micrographs for all systems are shown in Fig. $2 a-h$ in which a similar morphology of Nps can be observed. The coating of Nps with silica induced an increment in diameter size ( $\sim 10.4 \mathrm{~nm}$ for $\left.\gamma-\mathrm{Fe}_{2} \mathrm{O}_{3} @ \mathrm{SiO}_{2} \mathrm{Nps}\right)$ with respect to the $\gamma$ $\mathrm{Fe}_{2} \mathrm{O}_{3}$ Nps. ${ }^{12}$ This is related to the drying and following redispersion of Nps in water for functionalization promoting the agglomeration among the Nps. From the particle size histogram, that was fitted to a Gaussian distribution function (see Fig. S1a-f $\dagger$ ), a mean diameter of $\sim 9 \mathrm{~nm}$ was estimated for the $\gamma-\mathrm{Fe}_{2} \mathrm{O}_{3}-2 \mathrm{Nps}$ which is greater than for the previously synthesized Nps $(\sim 6.8 \mathrm{~nm})^{\mathbf{1 2}}$ using the same method but a different base such as $\mathrm{NH}_{4} \mathrm{OH}$ (weak) and $\mathrm{NaOH}$ (strong base), indicating that the used base can slightly influence the final morphology of the obtained $\gamma-\mathrm{Fe}_{2} \mathrm{O}_{3} \mathrm{Nps} .{ }^{17}$ These results show that the coprecipitation method is a convenient procedure to obtain Nps with diameters less than $10 \mathrm{~nm}$. After coating with OA and LA, the mean particle diameter slightly decreased, what is expected since carboxylic acids act as dispersant or surfac-

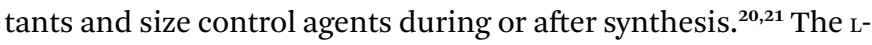
arg aminoacid seems to have the same effect on the $\gamma-\mathrm{Fe}_{2} \mathrm{O}_{3}$ Nps. This size-decreasing trend is also noticed from the Rietveld's refinement where a smaller mean crystallite size was also detected after functionalization (see Table 1). However, some diameters differ a little from the TEM values meaning that some Nps are composed at least of one or two crystallites. A similar result has been reported by López et al. using chitosan-coated magnetic Nps and also in our previous work for $\gamma-\mathrm{Fe}_{2} \mathrm{O}_{3}$ @HAp Nps. ${ }^{16,22}$ In addition, if OA and LA acids would have been added during the Nps synthesis the size distribution would be narrower, since these acids act as size control agents. ${ }^{17,20}$ It is also observed in TEM images (Fig. 2) that functionalized Nps show well-defined morphology in comparison to the uncoated one (Fig. 2b).

On the other side, the $\gamma-\mathrm{Fe}_{2} \mathrm{O}_{3} @ M W C N T$ s hybrid Nps clearly show the coexistence between o-MWCNTs and $\gamma-\mathrm{Fe}_{2} \mathrm{O}_{3} \mathrm{Nps}$ with quasi-spherical morphology. The Fig. $2 \mathrm{~g}$ and $\mathrm{h}$ show the Nps embedded in the pores of SBA-15 which mean pore size was estimated by using the B.J.H. model and gave an average of $9 \mathrm{~nm} .{ }^{13}$ Besides, as one can notice the SBA15 retained its 2D hexagonal structure after functionalization with $\gamma-\mathrm{Fe}_{2} \mathrm{O}_{3} \mathrm{Nps}$ as also shown by Yiu et al. ${ }^{23}$ The $\gamma-\mathrm{Fe}_{2} \mathrm{O}_{3}$-SBA15 contains $\gamma-\mathrm{Fe}_{2} \mathrm{O}_{3}$ Nps with sizes ranging from 5-9 $\mathrm{nm}$. In addition, the Energydispersive X-ray spectroscopy (EDX) spectrum (Fig. 2i) also confirms the presence of $\mathrm{Si}, \mathrm{Fe}$ and $\mathrm{O}$ atoms in the sample.

The $\zeta$-potential provides information about the charges located on the surface of the functionalized Nps, which is an important parameter that favors the colloidal stability in water. It is known that magnetic Nps have chemical affinity for amino and carboxyl groups. ${ }^{17,20}$ Thus, the $\zeta$-potential can give information on the nature of functional groups bound to the surface of the $\gamma-\mathrm{Fe}_{2} \mathrm{O}_{3} @ \mathrm{~L}$-arg Nps. The $\zeta$-potential values measured at $\mathrm{pH}=7$ are summarized in Table 2. The bare $\gamma-\mathrm{Fe}_{2} \mathrm{O}_{3} \mathrm{Nps}$ showed values of -5 and $-10 \mathrm{mV}$, indicating a negative surface at this $\mathrm{pH}$, probably due to the slight predominance of negative $\mathrm{O}^{-}$sites. The Nps coated with fatty acids showed negative $\zeta$-potential $(-40 \mathrm{mV})$ indicating a negative charge on the outermost particle surface. Capping agents such as fatty acids form a protective monolayer, where carboxylate $\left(\mathrm{R}-\mathrm{COO}^{-}\right)$groups are strongly bonded to the particles surface. ${ }^{24}$ Since zeta-potential was measured at $\mathrm{pH}=$ 7 , the negative charge is more likely to be from a second layer of fatty acid where their carboxylate ( $\mathrm{R}-\mathrm{COO})$ groups are facing the water, thus, providing hydrophilic properties to the particle. Recently, Chen et al. showed the presence of a bilayer oleic acid coated iron oxide Nps, where the outer layer is physically adsorbed on the first one through hydrophobic interaction of the surfactants tails. ${ }^{24}$

The mechanism of bonding of the first monolayer of fatty acids coating $\mathrm{Fe}_{3} \mathrm{O}_{4} \mathrm{Nps}$ have been studied previously by FTIR and it was found that the chemisorption occurred through a covalent bonding between iron and carboxyl's oxygens. ${ }^{25}$ The wavenumber difference, $\Delta$, between the antisymmetric $\nu_{\text {as }}(-$ $\left.\mathrm{COO}^{-}\right)$and symmetric $\nu_{\mathrm{s}}\left(\mathrm{COO}^{-}\right)$vibrations was used to determine the mode in which carboxylate binds to the metal oxide surface, a value of $194 \mathrm{~cm}^{-1}$ was calculated for both acids coating the Nps. Similar behaviors were observed by Bloemen et al. and Baccile et al. for carboxylate interacting with iron oxide surfaces. ${ }^{26,27}$ Besides, the $\mathrm{pH}$ stability of this hydrophilic $-\mathrm{COO}^{-}$ group was studied by Bloemen et al.,${ }^{26}$ the $\mathrm{COOH}$ group coating 

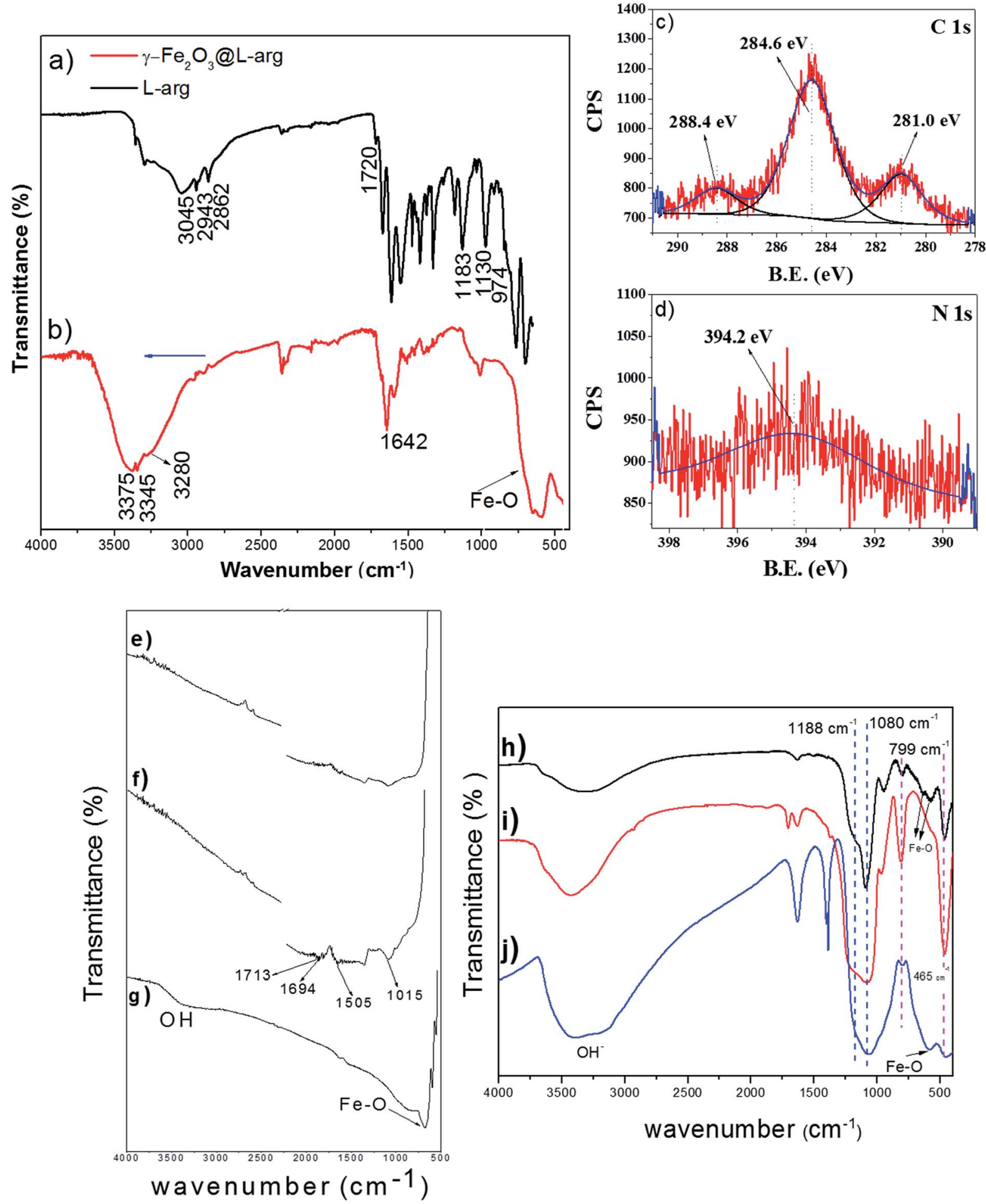

Fig. 3 FTIR of pure L-arg (a), $\gamma-\mathrm{Fe}_{2} \mathrm{O}_{3} \mathrm{OL}$-arg (b), $\mathrm{C}$ 1s and $\mathrm{N}$ 1s XPS regions for $\gamma-\mathrm{Fe}_{2} \mathrm{O}_{3} \mathrm{O}$ L-arg Nps (c and d), MWCNTs, FTIR signal in the range $2700-400 \mathrm{~cm}^{-1}$ is $5 \times$ enhanced (e), o-MWCNTs, FTIR signal in the range $2700-400 \mathrm{~cm}^{-1}$ is $5 \times$ enhanced (f), $\gamma$ - $\mathrm{Fe}_{2} \mathrm{O}_{3} @ M W C N T s(\mathrm{~g}), \gamma$-Fe $2^{-}$ $\mathrm{O}_{3} \mathrm{aSiO}_{2} \mathrm{Nps}(\mathrm{h})$, pure SBA15 (i) and $\gamma-\mathrm{Fe}_{2} \mathrm{O}_{3}-\mathrm{SBA} 15$ (j).

the Nps showed to retain its negative charge even at low values of $\mathrm{pH}$.

On the other hand, the $\zeta$-potential for the $\gamma-\mathrm{Fe}_{2} \mathrm{O}_{3} @ \mathrm{SiO}_{2}$ and $\gamma-\mathrm{Fe}_{2} \mathrm{O}_{3} @ \mathrm{~L}$-arg $\mathrm{Nps}$ have values of $-28 \mathrm{mV}$. These values are near to the threshold of the colloidal stability in aqueous medium. Rehana et al. showed a positive zeta potential value of $+3.8 \mathrm{mV}$ for Nps coated with L-arg. ${ }^{20}$ This last result suggest that our method facilitate the bonding with the Nps through the amine functional groups because carboxylic groups are externally exposed in the surface, explaining the negative value. On 

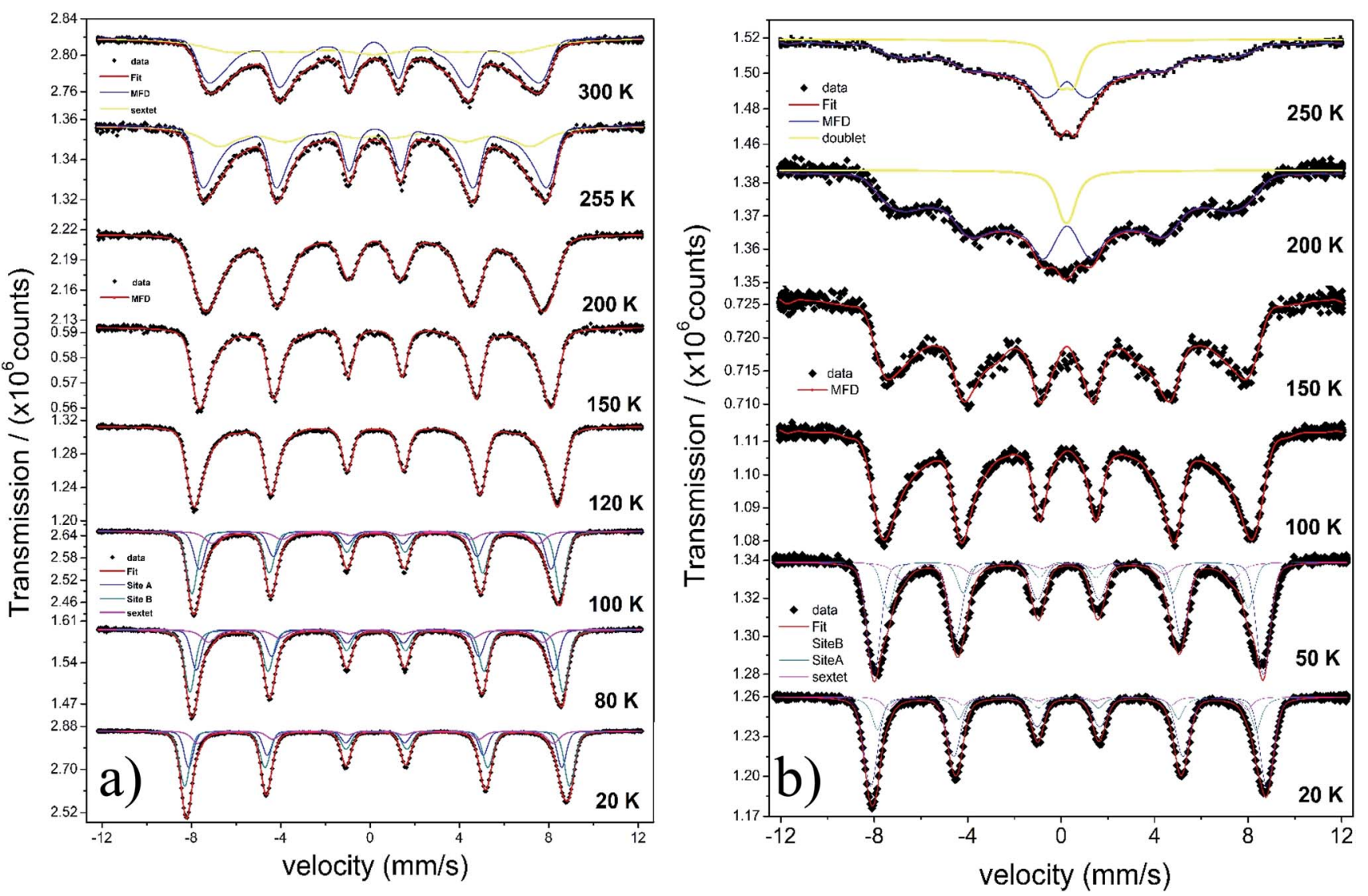

Fig. 4 Temperature dependence of Mössbauer spectra for $\gamma-\mathrm{Fe}_{2} \mathrm{O}_{3}-2$ (a) and $\gamma-\mathrm{Fe}_{2} \mathrm{O}_{3} @ \mathrm{OOA}(\mathrm{b})$.

the other hand, the $\gamma-\mathrm{Fe}_{2} \mathrm{O}_{3} @ M W C N T s$ hybrid Nps exhibited a value of $-52 \mathrm{mV}$, a result that is in close agreement with previous work for acid-treated MWCNTs indicating also the presence of carboxyl and hydroxyl groups. ${ }^{28}$

The mechanism of bonding between L-arg aminoacid and iron oxide Nps is rather more complex to explain; it is due to the presence of carboxylic, amine and guanidinium functional groups in L-arg. Park et al. have studied the interaction between Fe cations on the surface of magnetite Nps and L-glutamic and Llysine aminoacids and showed that the aminoacid-metal oxide interaction can be studied by $\zeta$-potential, proposing several bonding configurations. ${ }^{29}$

In order to get additional information and to investigate the plausible interaction between aminoacids and Nps in the present work, the FTIR spectrum for $\gamma-\mathrm{Fe}_{2} \mathrm{O}_{3} @ \mathrm{~L}$-arg Nps and pure arginine are displayed in Fig. 3a and b. For pure L-arg, the peaks at 2943 and $2862 \mathrm{~cm}^{-1}$ correspond to $\mathrm{CH}_{2}$ methylene antisymmetric and symmetric modes of stretching vibration, respectively. Fig. 3a depicts a wide band appearing centered around $3100 \mathrm{~cm}^{-1}$ assigned to $\nu$-NH stretching. The peaks in the region from 1000 to $1800 \mathrm{~cm}^{-1}$ are attributed to different alkyl, carboxyl and to amino vibration modes. ${ }^{30}$ Those bands below $1700 \mathrm{~cm}^{-1}$ are assigned to $\nu_{a s} \mathrm{COO}^{-}, \delta-\mathrm{NH}_{2}$ and $\mathrm{NH}^{3+}$ groups.

On the other side, in the FTIR spectrum for $\gamma-\mathrm{Fe}_{2} \mathrm{O}_{3}$ @L-arg Nps (Fig. 3b) the low IR region shows the characteristic $\mathrm{Fe}-\mathrm{O}$ bands of $\gamma-\mathrm{Fe}_{2} \mathrm{O}_{3} \mathrm{Nps}$ located at $650-700 \mathrm{~cm}^{-1}$. Besides, the strong peaks related to carboxyl vibrations signals, for pure $\mathrm{L}^{-}$ arg, in the region 1700 to $1000 \mathrm{~cm}^{-1}$ are significantly reduced. The decrease in the spectrum intensity is probably due to the partial dilution process of $\mathrm{L}$-arg in the synthesis of the Nps; thus, although the spectrum confirms the presence of $\mathrm{L}-\mathrm{arg}$, it is not possible to establish a bonding coordination due to the complexity of the spectrum.

Besides, the C 1s XPS shown in Fig. 3c exhibits a peak at $\sim 288.4 \mathrm{eV}$ related to bidentate carboxylate carbon of the $\mathrm{L}-\mathrm{arg}$ molecule onto Nps surface. ${ }^{31}$ Moreover, the presence of a broad $\mathrm{N} 1$ s peak at $\sim 394.2 \mathrm{eV}$ in the XPS spectra (Fig. $3 \mathrm{~d}$ ) indicates that the nitrogen $(\mathrm{NH})$ from the L-arg is also coordinating with the Nps since according to Wang et al. the binding energy of $\mathrm{N} 1 \mathrm{~s}$ should show a shift from $398.9 \mathrm{eV}$ to lower values by $1-3 \mathrm{eV}$ when nitrogen is bound to metals, because of a transfer of electron density from nitrogen to metals. ${ }^{32,33}$ This is in agreement with the zeta potential results. Wang et al. mentioned that during Nps nucleation the $\mathrm{Fe}_{3} \mathrm{O}_{4}$-amino/guanidine complexes exist transitorily. ${ }^{32}$ However, at the end of the synthesis the carboxyl groups of $\mathrm{L}$-arg should replace the amine/guanidine groups to form carboxyl-capped $\mathrm{Fe}_{3} \mathrm{O}_{4}$ Nps. The molar ratio used in our work for $\mathrm{Fe}^{2+} / \mathrm{Fe}^{3+} / \mathrm{L}$-arg was $1: 2: 0.5$ and the reaction time was $1 \mathrm{~h}$. Wang et al. ${ }^{32}$ used a molar ratio of $1: 2$ for $\mathrm{Fe}^{2+} / \mathrm{L}$-arg and a reaction time of $3 \mathrm{~h}$ for their synthesis as an optimum time parameter to get colloidal stability between carboxyl and amine/guanidine groups. In our case, this lack of 

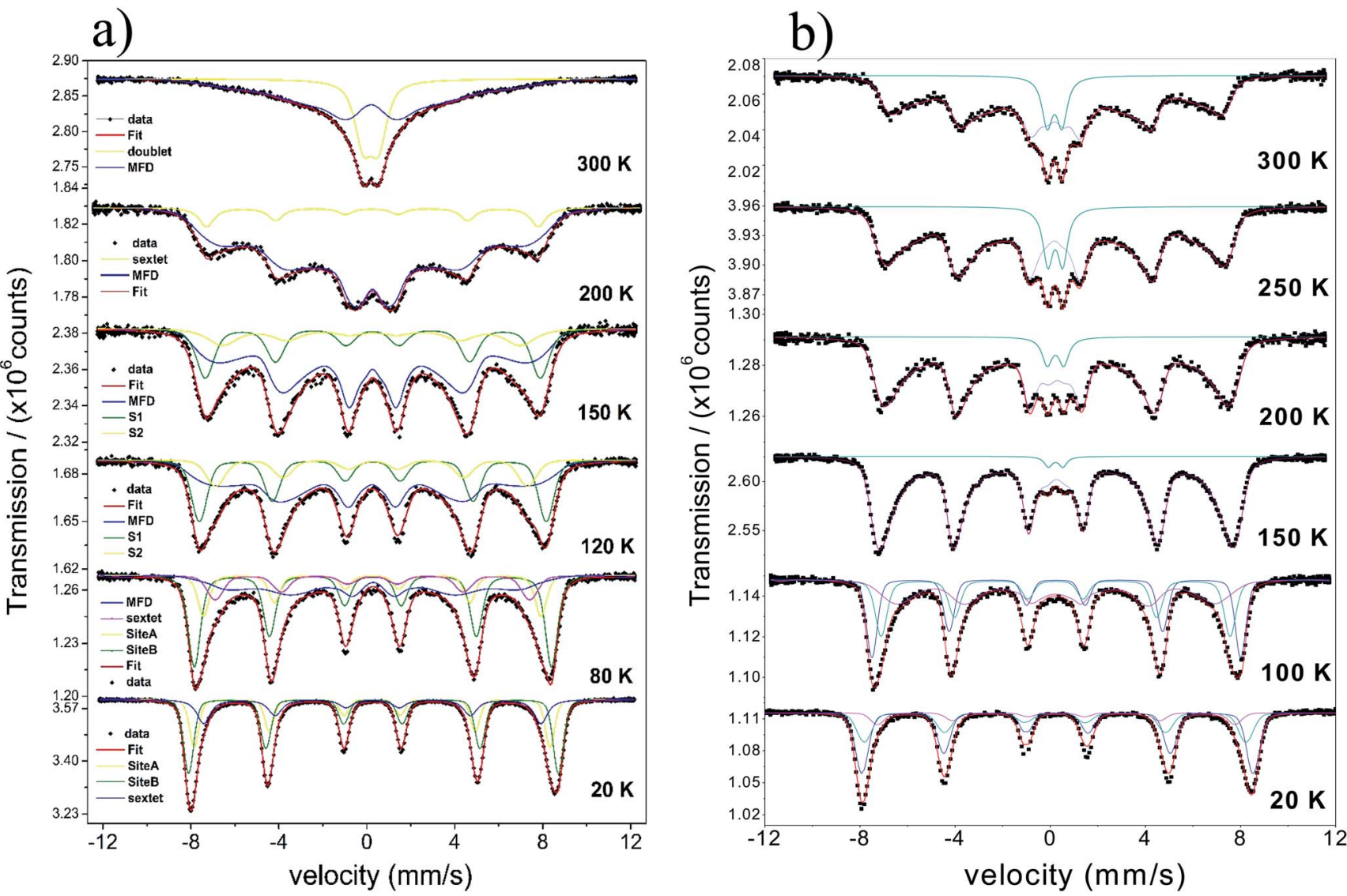

Fig. 5 Temperature dependence of Mössbauer spectra for (a) $\gamma-\mathrm{Fe}_{2} \mathrm{O}_{3} \mathrm{QLA}$ and (b) $\gamma$ - $\mathrm{Fe}_{2} \mathrm{O}_{3} \mathrm{aMWCNTs} \mathrm{Nps.}$

stability is observed in the zeta potential value of $-28 \mathrm{mV}$ where some carboxyl groups are found in a free configuration mode.

The FTIR spectrum displayed in (Fig. 3g) indicates the sorption of Nps onto MWCNTs backbone. The IR spectrum for pristine MWCNTs (Fig. 3e) shows a broader peak at around 1500 $\mathrm{cm}^{-1}$ related to $\mathrm{C}=\mathrm{C}$ stretching of carbon skeleton. ${ }^{34}$ In the spectrum of Fig. 3f, the vibrations modes located within 1500$1000 \mathrm{~cm}^{-1}$ belong to $\mathrm{C}-\mathrm{O}$ bonds in the o-MWCNTs. The carboxyl groups $(\mathrm{COOH})$ formed after acidic treatment of MWCNTs with $\mathrm{HNO}_{3}$ produced IR peaks at 1694 and $1713 \mathrm{~cm}^{-1}$ due to stretching vibrations of $\delta(\mathrm{OH})$ and $\nu(\mathrm{C}=\mathrm{O})$. In Fig. $3 \mathrm{~g}$, a strong band of $\gamma-\mathrm{Fe}_{2} \mathrm{O}_{3}$ at $683 \mathrm{~cm}^{-1}$ was noted. However, the bands related to MWCNTs treated with acid practically disappeared. This decrease could be attributed to an ester linkage configuration between the o-MWCNTs and $\gamma-\mathrm{Fe}_{2} \mathrm{O}_{3}$ NPs, as suggested by Shan et al. ${ }^{34}$ However, the reduction of intensity for some bands of the o-MWCNTs because of the amount of iron on the sample, resulting from the synthesis, and reflected in the strong broad band between $600-700 \mathrm{~cm}^{-1}$ that cannot be ignored.

The FTIR spectra of $\mathrm{SiO}_{2}$ coated $\gamma-\mathrm{Fe}_{2} \mathrm{O}_{3}$ Nps are presented in Fig. 3h. The IR position of $\mathrm{SiO}_{2}$ vibration bands are similar to those observed for pure SBA15 and $\gamma-\mathrm{Fe}_{2} \mathrm{O}_{3}$-SBA15 (Fig. 3i and j). The characteristic peaks of the $\gamma-\mathrm{Fe}_{2} \mathrm{O}_{3} \mathrm{Nps}$ at 635, 573 and 464 $\mathrm{cm}^{-1}$ are due to the stretching vibrations of $\mathrm{Fe}-\mathrm{O}$ in octahedral and tetrahedral sites of $\gamma-\mathrm{Fe}_{2} \mathrm{O}_{3} \cdot{ }^{35}$ The peak at $799 \mathrm{~cm}^{-1}$ is
Table 3 Mössbauer hyperfine parameters for all samples at $20 \mathrm{~K}$. The $\delta$ value is relative to $\alpha$-Fe. Site A (tetrahedral sites), Site B (octahedral sites). MFD: magnetic field distribution

\begin{tabular}{llllll}
\hline sample & Component & $\begin{array}{l}\text { RAA } \\
(\%)\end{array}$ & $\begin{array}{l}\delta \\
\left(\mathrm{mm} \mathrm{s}^{-1}\right)\end{array}$ & $\begin{array}{l}B_{\mathrm{hf}} \\
(T)\end{array}$ & $\begin{array}{l}\text { QS } \\
\left(\mathrm{mm} \mathrm{s}^{-1}\right)\end{array}$ \\
\hline$\gamma-\mathrm{Fe}_{2} \mathrm{O}_{3}-1$ & A & 26 & 0.40 & 50.4 & -0.021 \\
& B & 59 & 0.41 & 52.4 & 0.02 \\
$\gamma-\mathrm{Fe}_{2} \mathrm{O}_{3} @ \mathrm{SiO}_{2}$ & Sextet & 15 & 0.36 & 47.7 & 0.004 \\
$\gamma-\mathrm{Fe}_{2} \mathrm{O}_{3}-2$ & MFD & 100 & 0.42 & 52.9 & 0.002 \\
& A & 31 & 0.38 & 51.9 & 0 \\
& B & 52 & 0.45 & 53.6 & 0.03 \\
$\gamma-\mathrm{Fe}_{2} \mathrm{O}_{3} @ \mathrm{OA}$ & Sextet & 17 & 0.40 & 49.5 & 0 \\
& A & 25 & 0.39 & 50.4 & -0.072 \\
$\gamma-\mathrm{Fe}_{2} \mathrm{O}_{3} @ L A$ & B & 65 & 0.43 & 52.7 & 0.013 \\
& Sextet & 10 & 0.42 & 47.8 & 0.028 \\
$\gamma-\mathrm{Fe}_{2} \mathrm{O}_{3} @ \mathrm{~A}-\mathrm{arg}$ & A & 29 & 0.40 & 51.7 & -0.01 \\
& Sextet & 48 & 0.45 & 53.7 & 0.03 \\
& A & 23 & 0.41 & 49.7 & -0.01 \\
$\gamma-\mathrm{Fe}_{2} \mathrm{O}_{3} @ M W C N T S$ & 28 & 0.33 & 49.4 & -0.018 \\
& B & 64 & 0.50 & 51.4 & 0.02 \\
$\gamma-\mathrm{Fe}_{2} \mathrm{O}_{3}$-SBA15 & Sextet & 8 & 0.35 & 47 & -0.005 \\
& B & 31 & 0.31 & 49.9 & 0.002 \\
& Sextet & 57 & 0.41 & 51.1 & 0.017 \\
& A & 22 & 0.36 & 46.7 & 0 \\
& B & 37 & 0.37 & 49.8 & 0.001 \\
& Sextet & 41 & 0.37 & 52.3 & 0 \\
& & & & 46.6 & 0
\end{tabular}



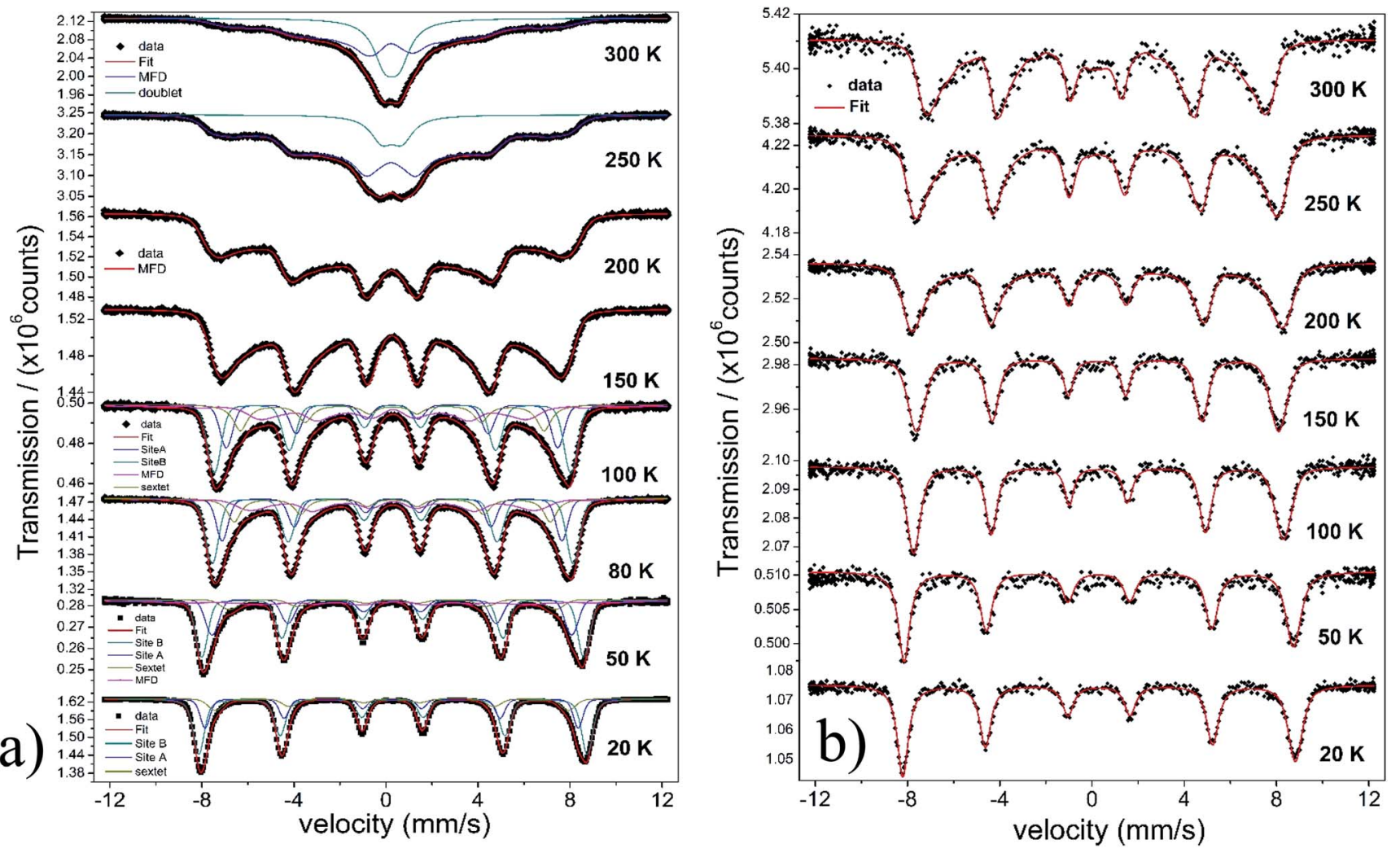

Fig. 6 Temperature dependence of Mössbauer spectra for $\gamma-\mathrm{Fe}_{2} \mathrm{O}_{3}-1$ (a) and $\gamma-\mathrm{Fe}_{2} \mathrm{O}_{3} @ \mathrm{CSiO}_{2} \mathrm{Nps}$ (b).

related to the bending vibration of $\mathrm{Si}-\mathrm{O}-\mathrm{Si}$ and the overlap shoulder at $465 \mathrm{~cm}^{-1}$ to $\mathrm{O}-\mathrm{Si}-\mathrm{O}$ bond, the strong band and the shoulder at $1080 \mathrm{~cm}^{-1}$ and $1188 \mathrm{~cm}^{-1}$ reflect the presence of asymmetrical and symmetrical $\mathrm{Si}-\mathrm{O}-\mathrm{Si}$ stretching modes. ${ }^{36} \mathrm{It}$ can be seen that the characteristic peaks of $\gamma-\mathrm{Fe}_{2} \mathrm{O}_{3}$ Nps are shifted to higher frequencies from 634 to $636 \mathrm{~cm}^{-1}$ and 567 to $576 \mathrm{~cm}^{-1}$, respectively. However, the band at $464 \mathrm{~cm}^{-1}$ for Fe-O vibrations remained unchanged after coating and deposition of the Nps with $\mathrm{SiO}_{2}$ and SBA15.

The temperature dependence of the Mössbauer spectra of pure $\gamma-\mathrm{Fe}_{2} \mathrm{O}_{3}-1, \gamma-\mathrm{Fe}_{2} \mathrm{O}_{3} @ \mathrm{OA}$ and $\gamma-\mathrm{Fe}_{2} \mathrm{O}_{3}$-LA are typical for Nps with diameters smaller than $10 \mathrm{~nm}$ (see Fig. 4b, 5a and 6a). At 20 $\mathrm{K}$ the spectra can be fitted with two sextets related to $\mathrm{A}\left(\mathrm{Fe}^{(\mathrm{III})}\right.$ in a tetrahedral oxygen coordination) and B sites ( $\mathrm{Fe}^{(\mathrm{III})}$ in a octahedral coordination) (see hyperfine parameters in Table 3) and the third sextet is related to surface Fe atoms with canted spin structure. At temperatures above $200 \mathrm{~K}$ the spectral peaks become broadened indicating the onset of superparamagnetic fluctuations overcoming the magnetic anisotropy barrier of magnetic particles and at $300 \mathrm{~K}$ the relaxation-broadened magnetic pattern has similar area as the superparamagnetic contribution with collapsed hyperfine splitting. The rather continuous spectral development with temperature is typical for Nps that are magnetically interacting. Therefore, a distinct separation of magnetically frozen and superparamagnetic fractions cannot be made.

This is in contrast to the $\gamma-\mathrm{Fe}_{2} \mathrm{O}_{3} @ M W C N T$ nanohybrids. As seen in Fig. 5b, there can clearly distinguish a superparamagnetic doublet structure at the center of the magnetically split spectrum above $c a .150 \mathrm{~K}$ indicating that at least part of the Nps are only weakly magnetically coupled. The doublet area increases with temperature, however, even at $300 \mathrm{~K}$ the magnetically split contribution stays dominant. This means that the blocking temperature on the time scale of hyperfine interactions has to be above room temperature. The spectra of $\gamma-\mathrm{Fe}_{2} \mathrm{O}_{3}-1$ and $\gamma-\mathrm{Fe}_{2} \mathrm{O}_{3} @ \mathrm{SiO}_{2}$ Nps are shown in Fig. 6a and b. The spectra for the $\gamma-\mathrm{Fe}_{2} \mathrm{O}_{3} @ \mathrm{SiO}_{2} \mathrm{Nps}$ phase was fitted using a hyperfine magnetic field distribution (MFD) with hyperfine magnetic fields and isomers shifts close to those found in the spectra for pure for $\gamma-\mathrm{Fe}_{2} \mathrm{O}_{3}-1$ Nps (see Fig. 6a and Table 3). The temperature dependence of spectral shape, however, differs from that of the pure $\gamma-\mathrm{Fe}_{2} \mathrm{O}_{3} \mathrm{Nps}$ (Fig. 6b). Up to $250 \mathrm{~K}$ no indication of overbarrier fluctuations is found and the $B_{\mathrm{hf}}$ distributions are typical for Nps bigger than $10 \mathrm{~nm} .{ }^{8}$ This result suggests that clustering of particles ocurred during functionalization with $\mathrm{SiO}_{2}$, as also evidenced through the TEM analysis. For uncoated $\gamma-\mathrm{Fe}_{2} \mathrm{O}_{3}-1$ Nps a fitting model containing A and B sites seems to be suitable. However, for measurements performed at temperatures above $80 \mathrm{~K}$ a MFD component due overbarrier fluctuations was added, this subspectra is related to the very small particles (Fig. 6a).

The Mössbauer spectra of all samples (except $\gamma-\mathrm{Fe}_{2} \mathrm{O}_{3} @ \mathrm{SiO}_{2}$ $\mathrm{Nps}$ ) measured at $20 \mathrm{~K}$ were fitted using three magnetic components (Fig. 4a, b, 5a, b, 6a and 7), two sextets related to Fe in tetrahedral and octahedral coordination of maghemite, and a third sextet related to a spin disordered surface layer. In fact, 


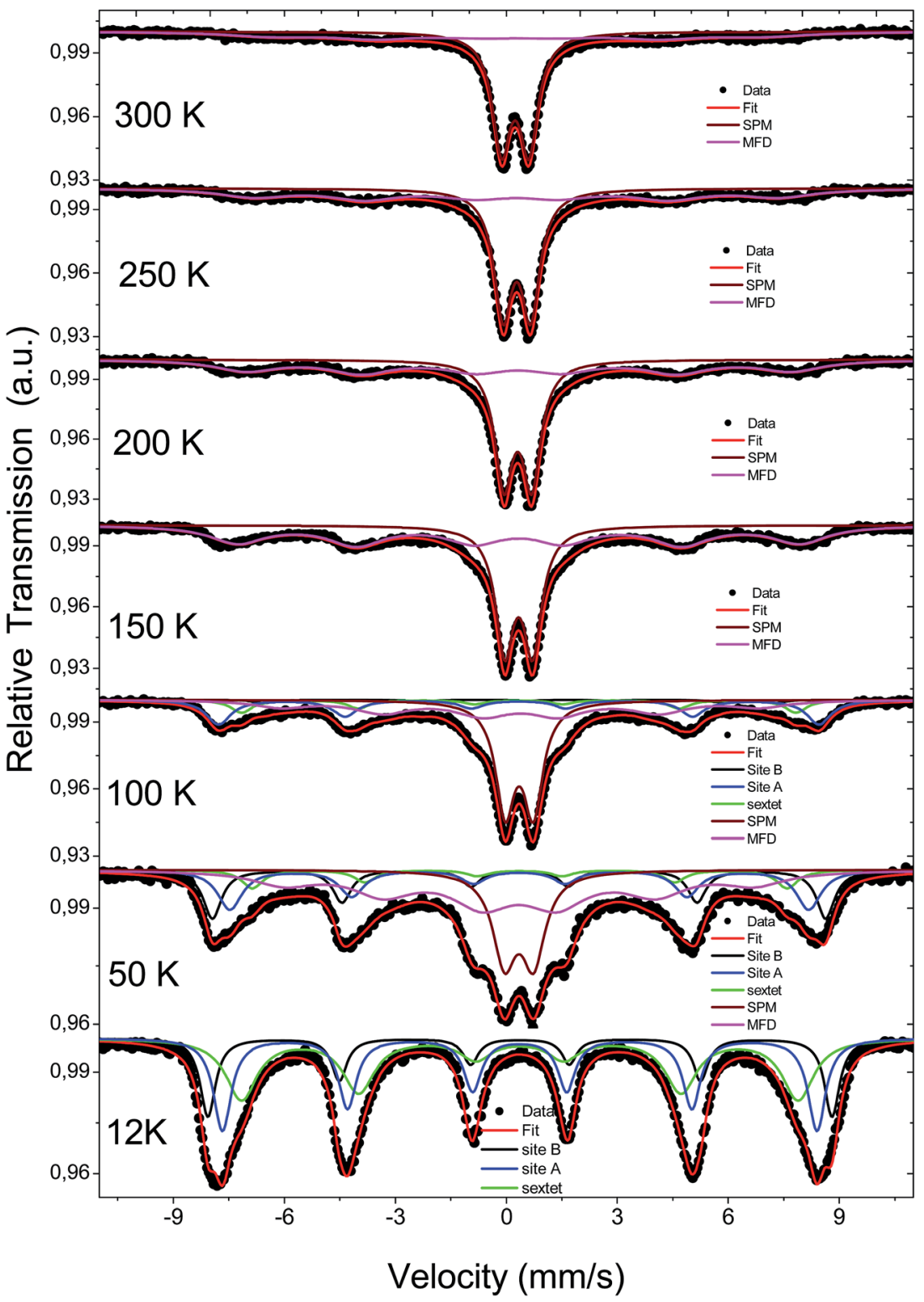

Fig. 7 Temperature dependence of Mössbauer spectra for sample $\gamma-\mathrm{Fe}_{2} \mathrm{O}_{3}-\mathrm{SBA} 15$.

the disordered phase in maghemite Nps has been reported in many works. Recently, measurements of polarized small-angle neutron scattering (SANSPOL) and nuclear spin forward (NSF) showed that the presence of spin disordered layer reduced the magnetization to $\sim 50 \%$ of the bulk value..$^{37}$ In the present paper, above $20 \mathrm{~K}$, the Mossbauer spectra showed the presence of a fourth component that is related to fast relaxing magnetic small nanoparticles. This component is implemented through a MFD. This last component increases with temperature leading a reduced areas values for the A and B iron sites. As one can note, the $\gamma$ $\mathrm{Fe}_{2} \mathrm{O}_{3}$-SBA15 sample shows the largest paramagnetic component at room temperature, among all the samples considered in this work. This is because the maghemite Nps were grown in the pores of the SBA15 structure. The Fig. 2h shows a SBA15 particle with nicely ordered pores. These pores have an average distance of $9.6 \mathrm{~nm}$, the inset of Fig. 2h shows the gray profile obtained from the yellow reference line, the distance from the first to the eleventh pore was of $105.6 \mathrm{~nm}$, and therefore, the maghemite particles should have particle size smaller than $9.6 \mathrm{~nm}$.

In short, Mössbauer spectroscopy allows to distinguish various iron oxides from their differing hyperfine parameters. According to our previous works and other literatures, we noticed that the air exposure (time of several days after synthesis) and high chemical reactivity of the magnetite's nanoscopic surface lead inevitably to complete oxidation to maghemite. ${ }^{\mathbf{1 2 , 1 6 , 1 7 , 3 8}}$ As described by da Costa et al. it seems that once oxidation begins at the surface it will extend to the entire particle volume. ${ }^{38}$ In our case all isomer shift values determined from fits indicate that the samples are composed of maghemite. We have not found indication for divalent iron that should be present in magnetite. The Relative Absorption Area (RAA) at 20 $\mathrm{K}$ for site $\mathrm{B}$ was bigger than site $\mathrm{A}$, respectively. The isomer shift 

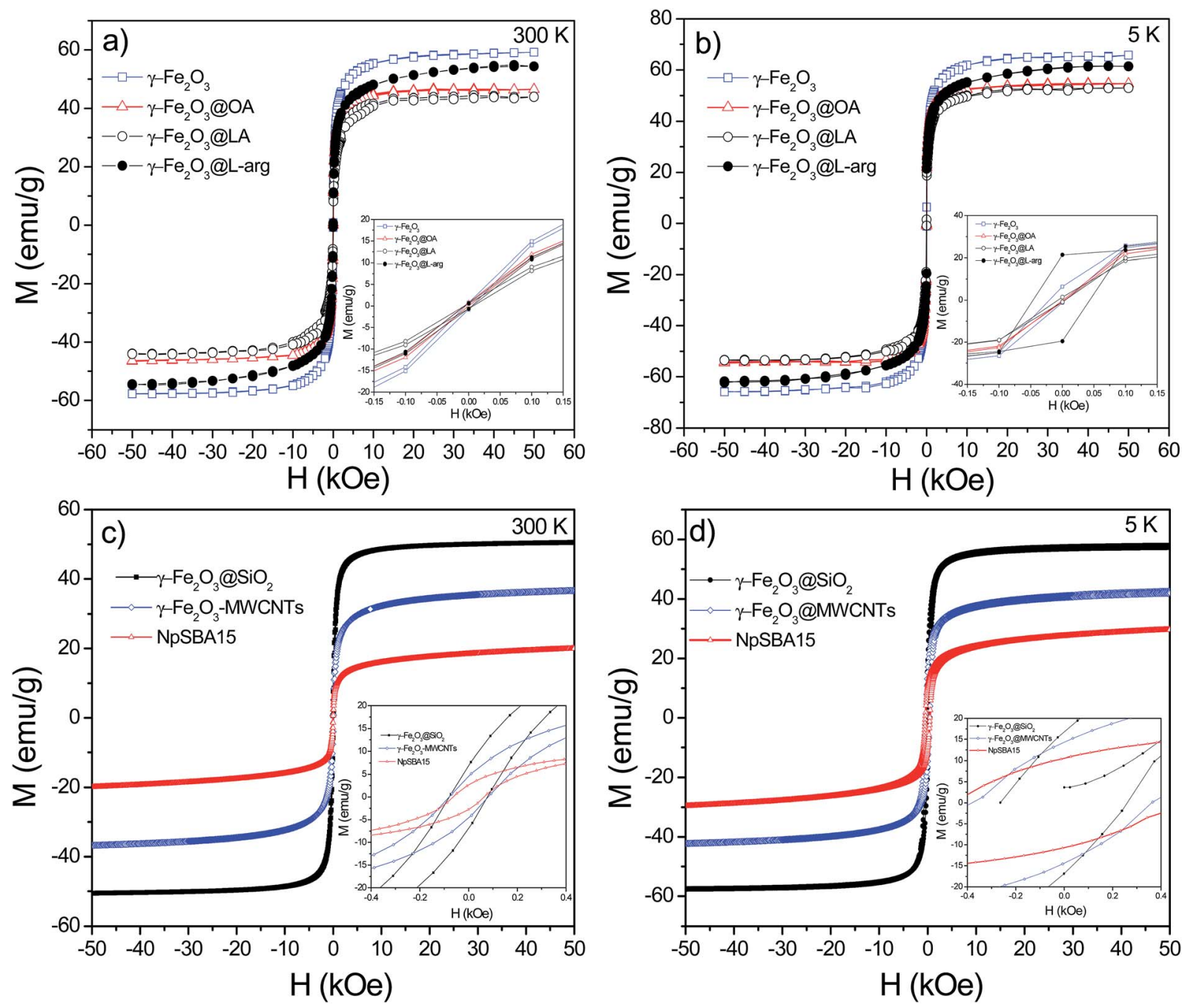

Fig. $8 \mathrm{M}-\mathrm{H}$ loops at RT and $5 \mathrm{~K}$ for $\gamma-\mathrm{Fe}_{2} \mathrm{O}_{3}-2, \gamma-\mathrm{Fe}_{2} \mathrm{O}_{3} \mathrm{QOA}, \gamma-\mathrm{Fe}_{2} \mathrm{O}_{3} \mathrm{aLA}, \gamma-\mathrm{Fe}_{2} \mathrm{O}_{3} \mathrm{CL}$-arg (a and b) and $\mathrm{M}-\mathrm{H}$ loops at RT and $5 \mathrm{~K}$ for $\gamma-$ $\mathrm{Fe}_{2} \mathrm{O}_{3} \mathrm{CSiO}_{2}, \gamma-\mathrm{Fe}_{2} \mathrm{O}_{3} \mathrm{QMWCNTs}$ and $\gamma-\mathrm{Fe}_{2} \mathrm{O}_{3}-\mathrm{SBA} 15$ (c and d).

$(\delta)$ values ranged from 0.31 to $0.40 \mathrm{~mm} \mathrm{~s}^{-1}$ for sites A and 0.41 to $0.50 \mathrm{~mm} \mathrm{~s}^{-1}$ for site $\mathrm{B}$. Also, the hyperfine magnetic fields $\left(B_{\mathrm{hf}}\right)$ were found to be consistent for sites A and B in inverse cubic spinel maghemite. The third sextet included in the fitting, that corresponds to the outermost layers, have RAA, $\delta$ and $B_{\mathrm{hf}}$ ranging from 8 to $24 \%, \delta=0.35$ to $0.42 \mathrm{~mm} \mathrm{~s}^{-1}$ and $B_{\mathrm{hf}}=47.7$ to $49.5 \mathrm{~T}$, respectively.

Table 2 summarizes the saturation magnetization $\left(M_{\mathrm{s}}\right)$ obtained from the law of approach to saturation (LAS) by fitting the M-H loops (see Fig. 8) at $300 \mathrm{~K}$ with the equation: ${ }^{39}$

$$
M=M_{\mathrm{s}}\left(1-\frac{b}{H^{2}}\right)+\chi H
$$

where $\chi$ is the paramagnetic susceptibility and $b$ is related to the magneto-crystalline anisotropy. ${ }^{16,17,35}$

The $M_{\mathrm{s}}$ values for uncoated $\gamma-\mathrm{Fe}_{2} \mathrm{O}_{3}$ Nps ranged from 59-62 emu g ${ }^{-1}$. A significant decrease in the $M_{\mathrm{s}}$ value was observed for $\gamma-\mathrm{Fe}_{2} \mathrm{O}_{3}-1 \mathrm{Nps}$ after coating with a $\mathrm{SiO}_{2}$ shell of $8 \mathrm{~nm}$ (average value, see inset in Fig. 2a) according to TEM results. Similarly, for $\gamma-\mathrm{Fe}_{2} \mathrm{O}_{3}-2$ the $M_{\mathrm{S}}$ values decreased after coating with carboxyl OA and LA acids. Nevertheless, the $\gamma-\mathrm{Fe}_{2} \mathrm{O}_{3} @ \mathrm{Q}$-arg Nps exhibit a value of $54 \mathrm{emu} \mathrm{g}^{-1}$ which is higher than the previous functionalized system even to those Nps functionalized with MWCNTs (37 emu $\left.\mathrm{g}^{-1}\right){ }^{40}$ Besides, VSM measurements were performed in the as received MWCNTs, before functionalization with $\gamma-\mathrm{Fe}_{2} \mathrm{O}_{3} \mathrm{Nps}$, the measurement showed a ferromagnetic signal (see Fig. S2 $\dagger$ ). The value obtained from $\mathrm{M}-\mathrm{H}$ loops was $0.4 \mathrm{emu} \mathrm{g}^{-1}$, which may be assigned to Ni residues from metal catalyst used in the synthesis of carbon nanotubes. This result is consistent with the semi quantitative analysis made by EDX analysis (see Fig. S3†). On the other hand, at $300 \mathrm{~K}$, only samples $\gamma-\mathrm{Fe}_{2} \mathrm{O}_{3} @ M W C N T s$ and $\gamma$ $\mathrm{Fe}_{2} \mathrm{O}_{3} @ \mathrm{SiO}_{2}$ exhibit coercivity field values of $\sim 80$ Oe indicating that these particles are magnetically blocked, in agreement with their Mössbauer spectra recorded at $300 \mathrm{~K}$ that showed superparamagnetic and magnetic components with a large RAA for the magnetic component. At $5 \mathrm{~K}$, all samples have a $M_{\mathrm{r}} / M_{\mathrm{S}}$ ratio smaller than 0.5, indicating that these samples are aggregated, magnetic interacting among each other and do not follow the Stoner-Wohlfarth criteria for blocked superparamagnetic particles. At $300 \mathrm{~K}$, the other functionalized samples have coercivity 


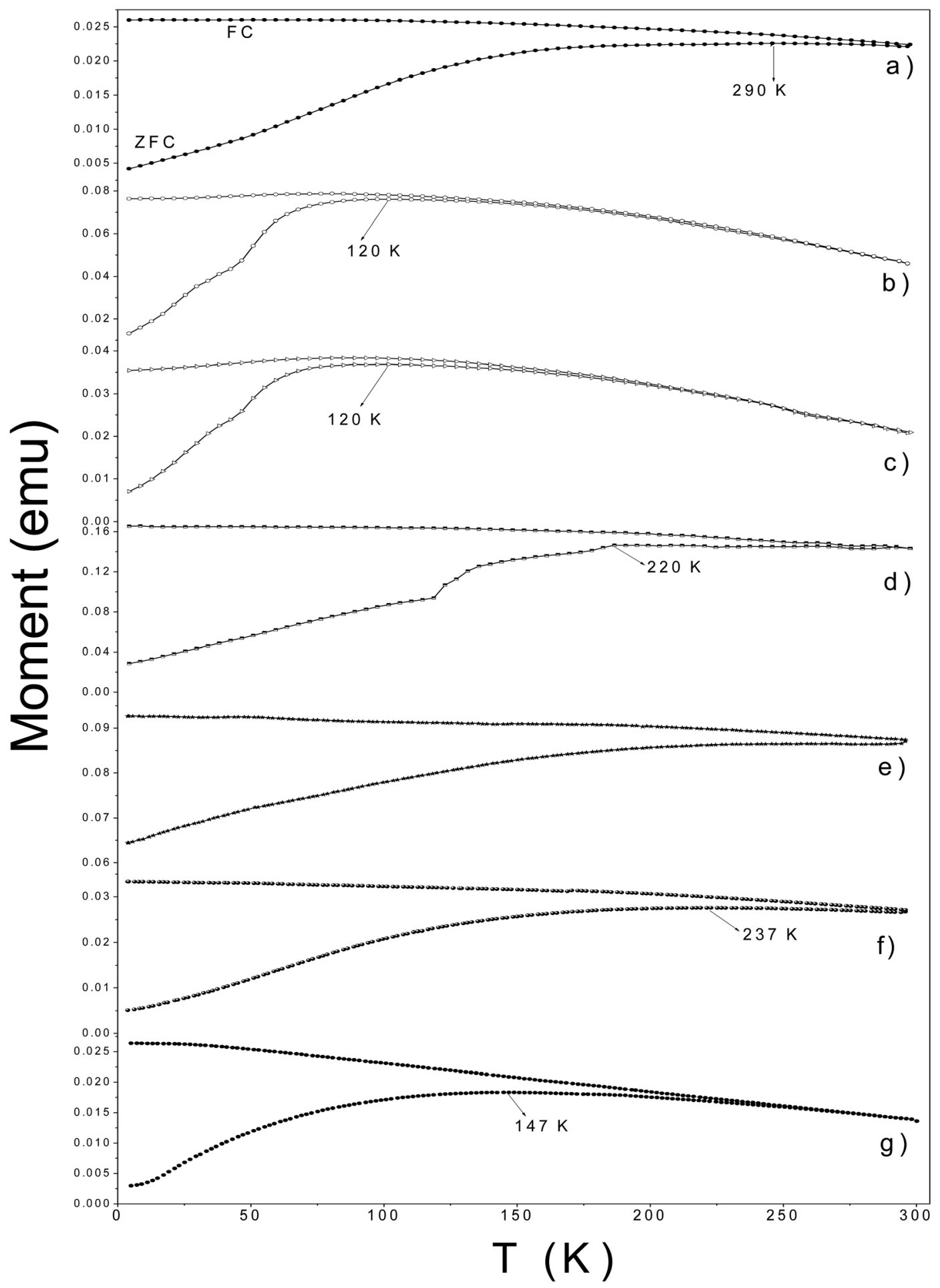

Fig. 9 ZFC and FC M-T measurements for $\gamma-\mathrm{Fe}_{2} \mathrm{O}_{3}-2$ (a), $\gamma-\mathrm{Fe}_{2} \mathrm{O}_{3} \mathrm{QOOA}$ (b), $\gamma-\mathrm{Fe}_{2} \mathrm{O}_{3} \mathrm{QLA}$ (c), $\gamma-\mathrm{Fe}_{2} \mathrm{O}_{3} \mathrm{aL}_{\mathrm{L}}-\mathrm{arg}(\mathrm{d}), \gamma-\mathrm{Fe}_{2} \mathrm{O}_{3} \mathrm{QSiO} \mathrm{O}_{2}(\mathrm{e}), \gamma-\mathrm{Fe}_{2}-$ $\mathrm{O}_{3}$ (aMWCNTs (f) and $\gamma-\mathrm{Fe}_{2} \mathrm{O}_{3}-\mathrm{SBA} 15$ (g). $\mathrm{H}_{\text {ext }}=80$ Oe.

values smaller than 15 Oe and therefore have a superparamagnetic like behavior. These results are in agreement with the smaller RAA for the blocked spectral component.

The temperature dependence of the magnetization is displayed in Fig. 9. In ZFC M-T measurements, all samples showed broad peaks below $300 \mathrm{~K}$. The temperature of the maximum in the ZFC M-T curve is assigned to the blocking like temperature $\left(T_{\mathrm{B}}\right)$ of Nps. The samples $\gamma-\mathrm{Fe}_{2} \mathrm{O}_{3} @ \mathrm{LA}, \gamma-\mathrm{Fe}_{2} \mathrm{O}_{3} @ \mathrm{OA}$ and $\gamma$ $\mathrm{Fe}_{2} \mathrm{O}_{3}$-SBA15 showed $T_{\mathrm{B}}$ like values smaller than $150 \mathrm{~K}$ indicating that these particles are smaller; Mössbauer spectra of these samples showed a strong superparamagnetic contribution at $300 \mathrm{~K}$. The irreversibility temperature where the ZFC and 


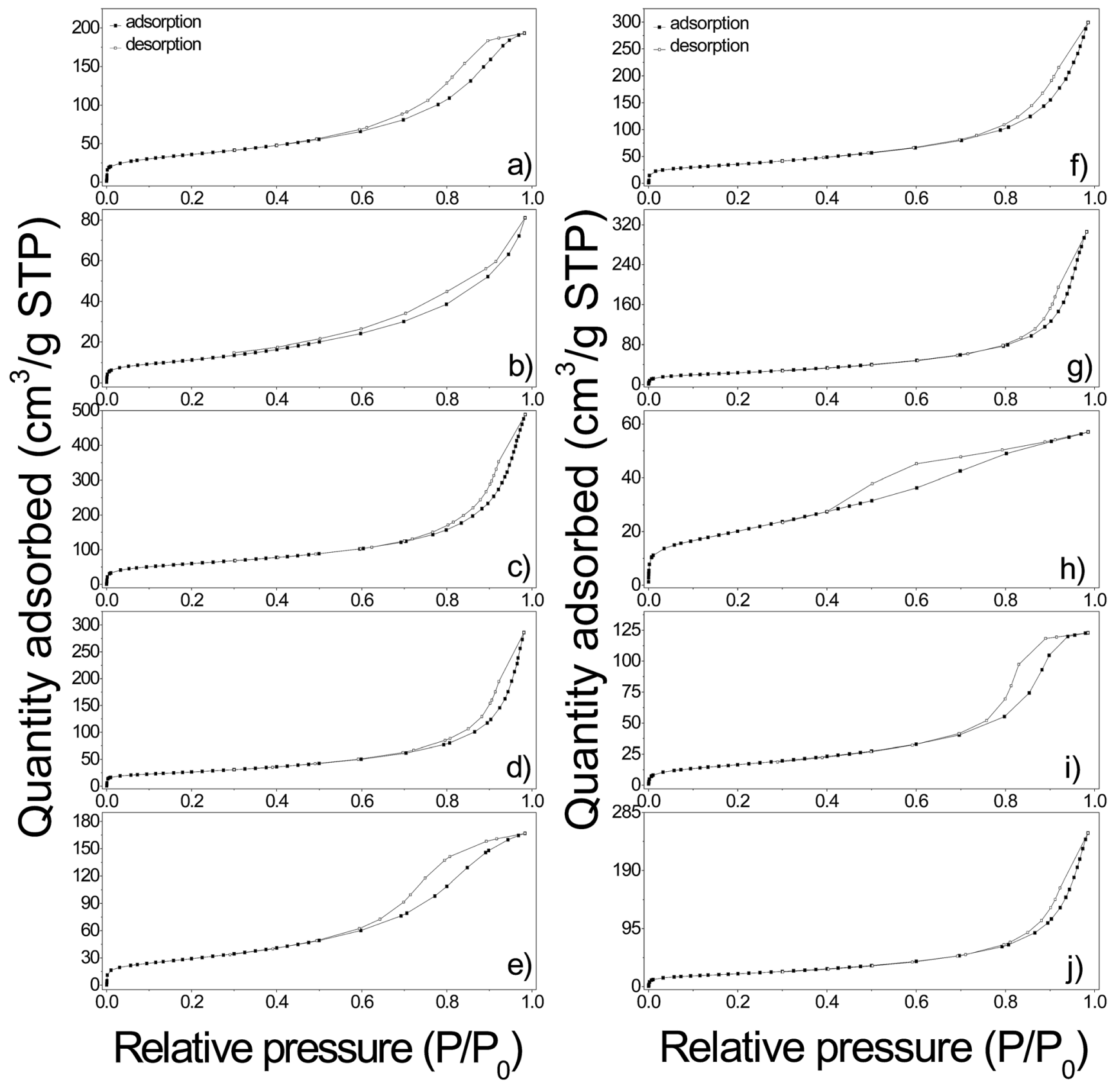

Fig. 10 Nitrogen adsorption-desorption isotherms at $77 \mathrm{~K}$ of $\gamma-\mathrm{Fe}_{2} \mathrm{O}_{3}-1$ (a), $\gamma-\mathrm{Fe}_{2} \mathrm{O}_{3} \mathrm{aSiO}_{2}$ (b), $\gamma-\mathrm{Fe}_{2} \mathrm{O}_{3}-\mathrm{SBA}_{15}$ (c), $\gamma-\mathrm{Fe}_{2} \mathrm{O}_{3} \mathrm{aHAp}$ (d), $\gamma-\mathrm{Fe}_{2} \mathrm{O}_{3}-$ EDTA1 (e), $\gamma-\mathrm{Fe}_{2} \mathrm{O}_{3} \mathrm{aMWCNTS}(\mathrm{f}), \gamma-\mathrm{Fe}_{2} \mathrm{O}_{3}-2$ (g), $\gamma-\mathrm{Fe}_{2} \mathrm{O}_{3} \mathrm{OOA}(\mathrm{h}), \gamma-\mathrm{Fe}_{2} \mathrm{O}_{3} \mathrm{QLA}$ (i) and $\gamma-\mathrm{Fe}_{2} \mathrm{O}_{3}(\mathrm{a} L-\arg$ (j).

FC $\mathrm{M}-\mathrm{H}$ curves depart from each other may be used as an indicator of the size distribution width. Thus, sample $\gamma-\mathrm{Fe}_{2} \mathrm{O}_{3}$ SBA15 seems to have a larger size distribution as compared with samples $\gamma-\mathrm{Fe}_{2} \mathrm{O}_{3} @ L A$ and $\gamma-\mathrm{Fe}_{2} \mathrm{O}_{3} @ \mathrm{OA}$. The others functionalized samples have a ZFC broad maximum at temperatures close and even above (sample $\gamma-\mathrm{Fe}_{2} \mathrm{O}_{3} @ \mathrm{SiO}_{2}$ ) room temperature. Since their particle sizes are similar, the peak position may result from the agglomeration of Nps. In samples $\gamma-\mathrm{Fe}_{2} \mathrm{O}_{3} @ \mathrm{~L}^{-}$ arg and $\gamma-\mathrm{Fe}_{2} \mathrm{O}_{3}$ @MWCNTs the agglomeration may be promoted by the aminoacid and the carboxyl functional groups decorated on the MWCNTs which can bond to two particles and bring them together. In the case of $\gamma-\mathrm{Fe}_{2} \mathrm{O}_{3} @ \mathrm{SiO}_{2}$, the difference between the point of zero charge of silica (at $\mathrm{pH}=$ 2.5) and $\gamma-\mathrm{Fe}_{2} \mathrm{O}_{3}($ at $\mathrm{pH}=7)$ may be the reason, at $\mathrm{pH}$ in between these values silica has negative charges on its surface and $\gamma-\mathrm{Fe}_{2} \mathrm{O}_{3}$ has positive charges, therefore there is an attractive electric force for clustering.

$\mathrm{N}_{2}$ adsorption-desorption isotherms and pore size distributions calculated by the B.J.H. method of pure and functionalized $\gamma-\mathrm{Fe}_{2} \mathrm{O}_{3}$ samples are shown in Fig. 10 and 11. The textural properties including B.E.T. specific surface area, pore volume and pore diameter are given in Table 2 . In general, the isotherms are classified as type II according to the IUPAC classification, attributed to slightly porous or macroporous solids. ${ }^{41}$ 

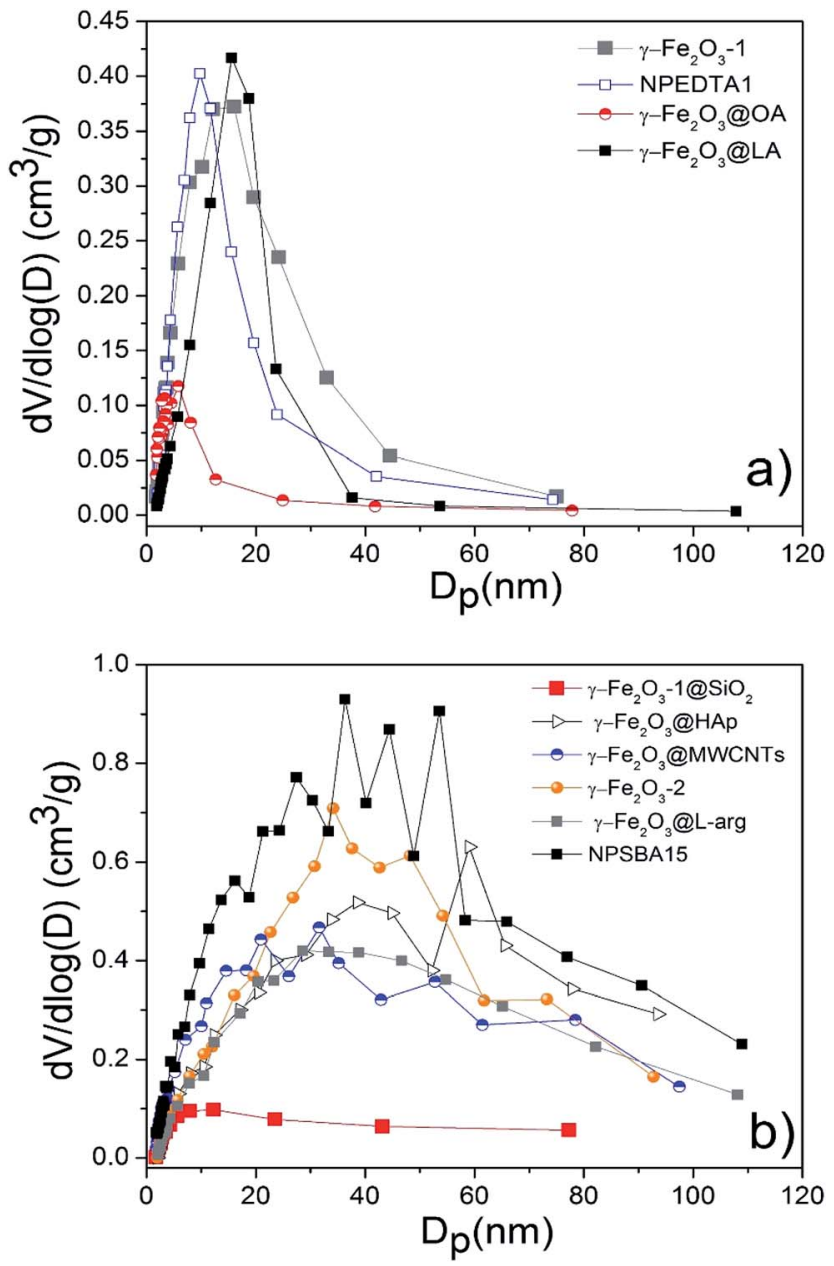

Fig. 11 Pore size distribution plots for all indicated samples. Nanoparticles with narrow (a) and broad (b) pore size distribution.

As it can be seen the isotherms showed a significant increment along with a hysteresis loop in the relative pressure region between 0.6 and 1 , indicating the presence of interparticle porosity probably due to the irregular agglomeration of nanoparticles resulting in a pore size wide distribution of mesopores and macropores (Fig. 11). The estimated pore diameters ranged from $4.7 \mathrm{~nm}$ to more than one hundred nanometers which confirmed the presence of mesopores in all the samples. The B.J.H. distributions as well as the isotherms of $\gamma-\mathrm{Fe}_{2} \mathrm{O}_{3}-1, \gamma$ $\mathrm{Fe}_{2} \mathrm{O}_{3}$-EDTA1, $\gamma-\mathrm{Fe}_{2} \mathrm{O}_{3} @ \mathrm{OA}$ and $\gamma-\mathrm{Fe}_{2} \mathrm{O}_{3} @ \mathrm{LA}$ indicated a more regular distribution of the formed pores giving pore sizes uniform values of $8.8,7.8,4.7$, and $10 \mathrm{~nm}$ respectively. The samples obtained magnetic Nps coated with L-arg, $\mathrm{HAp}, \mathrm{SiO}_{2}$ and the o-MWCNTs supporting the Nps display wider PSD indicating a more irregular agglomeration.

The $\gamma-\mathrm{Fe}_{2} \mathrm{O}_{3}-1$ Nps present a higher B.E.T. specific surface area of $129.7 \mathrm{~m}^{2} \mathrm{~g}^{-1}$ compared to $\gamma-\mathrm{Fe}_{2} \mathrm{O}_{3}-2 \mathrm{Nps}\left(88.3 \mathrm{~m}^{2} \mathrm{~g}^{-1}\right)$ synthesized by the same method, but using a different alkaline reagent. This change could be assigned to the difference in the mean particle size since $\gamma-\mathrm{Fe}_{2} \mathrm{O}_{3}-2 \mathrm{Nps}$ exhibited a larger diameter compared with $\gamma-\mathrm{Fe}_{2} \mathrm{O}_{3}-1$. These values are relatively higher than others found in the literature for magnetic nanoparticles. ${ }^{2}$ After coating $\gamma-\mathrm{Fe}_{2} \mathrm{O}_{3}-1$ with $\mathrm{SiO}_{2}$ the B.E.T. specific surface area exhibited a noticeable decrease $\left(42.3 \mathrm{~m}^{2}\right.$ $\mathrm{g}^{-1}$ ) along with a significant reduction in nitrogen adsorption, caused probably by the silica layer (thickness of $8 \mathrm{~nm}$ ) loaded onto Nps surface. The pure SBA15 sample has a specific BET surface of $790 \mathrm{~m}^{2} \mathrm{~g}^{-1},{ }^{13}$ and it considerably decreased to $214 \mathrm{~m}^{2}$ $\mathrm{g}^{-1}$ after functionalizing with maghemite Nps, this result may be related to the deposition of maghemite Nps in the SBA15 pores that induces a blocking of pore entrance or a simply reduction of the free volume inside pores. The functionalization with fatty acids (oleic and lauric acids) of $\gamma-\mathrm{Fe}_{2} \mathrm{O}_{3}-2 \mathrm{Nps}$ cause a slightly decrease in the B.E.T. specific surface area since the exposed area is covered by the carboxylic molecules resulting from functionalization. Similarly, the $\mathrm{L}$-arg aminoacid functionalized $\gamma-\mathrm{Fe}_{2} \mathrm{O}_{3}$ Nps exhibited the same behavior with a B.E.T. specific surface area of $77.5 \mathrm{~m}^{2} \mathrm{~g}^{-1}$.

On the other side, HAp functionalized $\gamma-\mathrm{Fe}_{2} \mathrm{O}_{3} \mathrm{Nps}$ exhibited a B.E.T. specific surface area of $95.5 \mathrm{~m}^{2} \mathrm{~g}^{-1}$, which is a higher value in comparison to those found in literature. ${ }^{42}$ The B.E.T. specific surface area value for $\gamma-\mathrm{Fe}_{2} \mathrm{O}_{3}$-EDTA1 indicates that EDTA strongly favor the increment in the B.E.T. specific surface area as a comparison with fatty and amino acids loaded onto Nps surface. In addition the sample $\gamma-\mathrm{Fe}_{2} \mathrm{O}_{3} @ M W C N T s$ nanohybrids shows an increment in the B.E.T. specific surface area $\left(129.6 \mathrm{~m}^{2} \mathrm{~g}^{-1}\right)$ respect to the MWCNTs without functionalization $\left(110 \mathrm{~m}^{2} \mathrm{~g}^{-1}\right)$.

Adsorption experiments were carried out for individual solutions of copper(II) and lead(II) at two different times in order to check the metal adsorption performance of functionalized nanoparticles. After adsorption not iron traces were found for the final $\mathrm{Cu}(\mathrm{II})$ and $\mathrm{Pb}$ (II) solutions in any case.

Copper was satisfactorily adsorbed onto uncoated and functionalized $\gamma-\mathrm{Fe}_{2} \mathrm{O}_{3}$ Nps. The final $\mathrm{Cu}$ (II) concentrations in the solutions and adsorption capacities for periods of 7 and $20 \mathrm{~h}$ are shown in Table 4 . The given values represent the average values determined for two independent experiments carried out with each sample during 7 and $20 \mathrm{~h}$ for the same initial concentration of $40 \mathrm{mg} \mathrm{L}^{-1}$. In general, an increment of the adsorbed amount was observed for larger times. In the comparison of results obtained for $\gamma-\mathrm{Fe}_{2} \mathrm{O}_{3}-1$ and $\gamma-\mathrm{Fe}_{2} \mathrm{O}_{3}-2$, it can be extracted that the mean particle size of uncoated maghemite Nps was not a key factor in the $\mathrm{Cu}$ (II) adsorption capacity since adsorbed amount is similar for both times. The samples containing $\mathrm{SiO}_{2}$ Nps and mesoporous SBA15 have comparable $\mathrm{Cu}$ (II) adsorption capacities as the bare Nps. As it can be seen, although all the functionalized systems adsorb significant quantities of $\mathrm{Cu}(\mathrm{II})$, the samples $\gamma-\mathrm{Fe}_{2} \mathrm{O}_{3} @ \mathrm{HAp}$ and $\gamma-\mathrm{Fe}_{2} \mathrm{O}_{3} @ \mathrm{~L}$-arg Nps showed the best performance achieving a high adsorption capacity of 73 and $88 \mathrm{mg} \mathrm{g}^{-1}$ after $20 \mathrm{~h}$ of contact.

For $\mathrm{Pb}$ (II) batch experiments all the final solutions showed $\mathrm{Pb}$ (II) concentrations lower than $0.05 \mathrm{mg} \mathrm{L}^{-1}$ from an initial concentration of $50 \mathrm{mg} \mathrm{L}^{-1}$, which means that all the $\mathrm{Pb}$ (II) species were adsorbed for the functionalized Nps. Although some of our samples showed small specific surface area values, their colloidal stability and zeta potential value allow for their adsorption capacity. One can notice that the fatty and amino 
Table $4 \mathrm{Cu}(\mathrm{II})$ adsorption capacity after 7 and $20 \mathrm{~h}$ of contact time. Initial concentration: $40 \mathrm{mg} \mathrm{L}^{-1}$ for both times. Adsorbent dose = $0.56 \mathrm{~g} \mathrm{~L}^{-1}$

\begin{tabular}{lllll}
\hline Adsorbent & $\begin{array}{l}C_{7} \\
\left(\mathrm{mg} \mathrm{L}^{-1}\right)\end{array}$ & $\begin{array}{l}q_{7} \\
\left(\mathrm{mg} \mathrm{g}^{-1}\right)\end{array}$ & $\begin{array}{l}C_{20} \\
\left(\mathrm{mg} \mathrm{L}^{-1}\right)\end{array}$ & $\begin{array}{l}q_{20} \\
\left(\mathrm{mg} \mathrm{g}^{-1}\right)\end{array}$ \\
\hline$\gamma-\mathrm{Fe}_{2} \mathrm{O}_{3}-1$ & 6 & 61.3 & 6.7 & 78 \\
$\gamma-\mathrm{Fe}_{2} \mathrm{O}_{3}-2$ & 8.3 & 57.1 & 11.5 & 69.3 \\
$\gamma-\mathrm{Fe}_{2} \mathrm{O}_{3} @ \mathrm{SiO}_{2}$ & 3.9 & 64.6 & 13.7 & 65.4 \\
$\gamma-\mathrm{Fe}_{2} \mathrm{O}_{3} @ \mathrm{OA}$ & 12.7 & 49.3 & 18.2 & 57.3 \\
$\gamma-\mathrm{Fe}_{2} \mathrm{O}_{3} @ L A$ & 8.1 & 57.5 & 15.2 & 62.7 \\
$\gamma-\mathrm{Fe}_{2} \mathrm{O}_{3} @ \mathrm{~L}$-arg & 3.3 & 66.1 & 9.6 & 72.6 \\
$\gamma-\mathrm{Fe}_{2} \mathrm{O}_{3} @ H A p$ & 0.3 & 71.5 & 1 & 88.2 \\
$\gamma-\mathrm{Fe}_{2} \mathrm{O}_{3}$-EDTA1 & 9 & 55.8 & 12.7 & 67.2 \\
$\gamma-\mathrm{Fe}_{2} \mathrm{O}_{3} @ M W C N T s$ & 5.5 & 62.1 & 13.3 & 66.2 \\
$\gamma-\mathrm{Fe}_{2} \mathrm{O}_{3}$-SBA15 & 2.3 & 62.5 & 2.9 & 61.4 \\
\hline
\end{tabular}

acids coated Nps which present negative charge at their surface, have strong electrostatic affinity for metal cations through the free carboxylate presented in the surface. Regarding the EDTA functionalized Nps, Dragan et al. reported the complexation of EDTA with metal cations occurs via a tetrahedral tetracoordinate complex with covalent $\mathrm{Pb}-\mathrm{N}$ bonds and ionic $\mathrm{Pb}$-carboxylate bonds. ${ }^{43}$ However, it is important to note that in the above configuration only two carboxyl groups of EDTA could participate while the remaining carboxyl groups are bond to Fe core through a monodentate configuration. ${ }^{17}$ In the case of nanoparticles functionalized with hydroxyapatite, HAp, it was proposed that $\mathrm{Pb}(\mathrm{II})$ adsorption occurred through an ion exchange reaction. The next irreversible equation is in general valid for the $\mathrm{pH}$ region between $\mathrm{pH}=3.0$ to $6.0 .^{44}$

$$
\mathrm{Ca}_{10}\left(\mathrm{POH}_{4}\right)_{6}(\mathrm{OH})_{2}+x \mathrm{~Pb}^{2+} \rightarrow x \mathrm{Ca}^{2+}+\mathrm{Ca}_{10-x} \mathrm{~Pb}_{x}\left(\mathrm{PO}_{4}\right)_{6}(\mathrm{OH})_{2}
$$

In our work, we used a $\mathrm{pH}=\mathbf{5 . 5}$ for the initial solution of $\mathrm{Pb}(\mathrm{II})$. The reaction could occur also for other divalent cations such as $\mathrm{Cu}$ (II). In the case of silica, it has an isoelectric point (p.z.c.) at $\mathrm{pH}=2.5$, above this point its surface is coated by $\mathrm{OH}^{-}$ groups favoring adsorption via electrostatic interaction with the metal cations. ${ }^{45}$

Moreover, maghemite Nps are not only used for magnetic separation purposes, they also present significant adsorption capabilities. Liu et al. found that $\mathrm{Cd}$ (II) was bound directly to $\mathrm{Fe}_{3} \mathrm{O}_{4}$ despite this was coated with humic acid. ${ }^{46}$ In our case $\gamma-\mathrm{Fe}_{2} \mathrm{O}_{3}-1$ and $\gamma-\mathrm{Fe}_{2} \mathrm{O}_{3}-2$ adsorbed better $\mathrm{Cu}$ (II) quantities than silica and MWCNTs bond to the Nps. It is worth mentioning that the surface chemical structure of maghemite presents $\mathrm{Fe}-\mathrm{OH}$ and $\equiv \mathrm{Fe}-\mathrm{O}^{-}$ sites, which act as a Lewis base. ${ }^{46}$ These functional groups can interact and coordinate with $\mathrm{Pb}$ (II) metal ions depending on the $\mathrm{pH}$ and p.z.c. of the adsorbent. ${ }^{47}$ The $\mathrm{pH}$ value of initial solutions is close to 5.5 , being the $\mathrm{Cu}^{2+}$ and $\mathrm{Pb}^{2+}$ the predominant species in solution. ${ }^{48}$ Regarding the p.z.c. of maghemite, it was reported to be $8.6,{ }^{45}$ thus particle surface is being likely a protonated surface at $\mathrm{pH}$ 5.5, so an electrostatic repulsion is expected. However, the affinity of metal ions to $\gamma-\mathrm{Fe}_{2} \mathrm{O}_{3}$ is higher than that of $\mathrm{H}^{+}$ions, indicating that metal ions replace the adsorbed $\mathrm{H}^{+}$ions from the Nps surface through an ion exchange mechanism. ${ }^{47,49}$

\section{Conclusions}

In this study, several $\gamma-\mathrm{Fe}_{2} \mathrm{O}_{3} \mathrm{Nps}$ functionalized with organic acids, aminoacid, silica and carbon nanotubes were successfully synthesized by the co-precipitation method, obtaining Nps with particle sizes ranging from 7-16 $\mathrm{nm}$ according to Rietveld refinement and TEM images analysis. The zeta potential studies and IR results showed that the functionalization was successful. The magnetic properties such as the saturation magnetization is affected by the surface's modification with carboxyl, aminoacid and silica. The $\gamma-\mathrm{Fe}_{2} \mathrm{O}_{3} \mathrm{Nps}$ displayed a superparamagnetic like behavior as proved by Mössbauer spectroscopy and ZFC M-T measurements. The functionalized $\gamma-\mathrm{Fe}_{2} \mathrm{O}_{3} \mathrm{Nps}$ exhibited BET specific surface area ranging from 74 to $214 \mathrm{~m}^{2} \mathrm{~g}^{-1}$ suitable for metal adsorption. All the nanomaterials present remarkable uptake capacities to adsorb $\mathrm{Cu}$ (II) and $\mathrm{Pb}$ (II) cations. Under the studied chemical conditions functionalized $\gamma-\mathrm{Fe}_{2} \mathrm{O}_{3} \mathrm{Nps}$ can significantly reduce the heavy metal concentration in solution, with $\mathrm{Pb}$ (II) being totally adsorbed after $7 \mathrm{~h}$ of interaction. Thus, it was concluded that these nanomaterials are promising to be applied for water remediation processes.

\section{Acknowledgements}

This work was partially supported by The National Council of Science, Technology and Technological Innovation (CONCYTEC/Cienciactiva-Peru). The authors wish to thank Dr Alexandre Mello by allow access to the X-ray photoelectron spectroscopy equipment of the Multiuser Laboratory of Surfaces and Nanostructures at CBPF. M. Morales thanks Conselho Nacional de Desenvolvimento Científico e Tecnológico (CNPq) for his fellowship, process number 305748/2015-7. F. J. Litterst and E. Sadrollahi are grateful for partial support by DAAD. This work was also supported by the Ministerio de Economía y Competitividad of Spanish Government through the research projects CTM2015-69246-R.

\section{Notes and references}

1 F. Fernández-Luqueño, F. López-Valdez, P. Gamero-Melo, S. Luna-Suárez, E. N. Aguilera-González, A. I. Martínez, M. García-Guillermo, G. Hernández-Martínez, R. HerreraMendoza, M. A. Álvarez-Garza and I. R. Pérez-Velázquez, Afr. J. Environ. Sci. Technol., 2013, 7, 567.

2 I. Ali, Chem. Rev., 2012, 112, 5073.

3 B. I. Kharisov, H. V. R. Dias, O. V. Kharissova, V. M. JiménezPérez, B. O. Pérez and B. M. Flores, RSC Adv., 2012, 2, 9325. 4 M. Arbabi and N. Golshani, Int. J. Epidemiol., 2016, 3, 283293.

5 L. J. Holcombe and G. P. Behrens, Environ. Prog., 1987, 6, 74. 6 M. M. Khin, A. S. Nair, V. J. Babu, R. Murugan and S. Ramakrishna, Energy Environ. Sci., 2012, 5, 8075.

7 W. Wu, Q. He and C. Jiang, Nanoscale Res. Lett., 2008, 3, 397. 8 S. Sun and H. Zeng, J. Am. Chem. Soc., 2002, 124, 8204.

9 R. A. Sperling and W. J. Parak, Philos. Trans. R. Soc., A, 2010, 368, 1333. 
10 J. A. R. Guivar, E. G. R. Fernandes and V. Zucolotto, Talanta, 2015, 141, 307.

11 Y. S. Kang, S. Risbud, J. F. Rabolt and P. Stroeve, Chem. Mater., 1996, 8, 2209.

12 J. A. R. Guivar, A. Bustamante, J. Flores, M. M. Santillan, A. M. Osorio, A. I. Martínez, L. Valladares and C. H. W. Barnes, Hyperfine Interact., 2014, 224, 89.

13 J. Aguado, J. M. Arsuaga, A. Arencibia, M. Lindo and V. Gascón, J. Hazard. Mater., 2009, 163, 213.

14 C. L. Chen, X. K. Wang and M. Nagatsu, Environ. Sci. Technol., 2009, 43, 2362.

15 C. Luo, Z. Tian, B. Yang, L. Zhang and S. Yan, Chem. Eng. J., 2013, 234, 256.

16 J. A. R. Guivar, E. A. Sanches, F. Bruns, E. Sadrollahi, M. A. Morales, E. O. López and F. Jochen Litterst, Appl. Surf. Sci., 2016, 389, 721.

17 J. A. Ramos Guivar, M. A. Morales and F. Jochen Litterst, J. Magn. Magn. Mater., 2016, 420, 324.

18 EPA, Method 200.7, Trace elements in water, solids and biosolids by inductively coupled plasma atomic emission spectrometry, EPA-821-R-01-010, January 2001.

19 T. Zhao, C. Hou, H. Zhang, R. Zhu, S. She, J. Wang, T. Li, Z. Liu and B. Wei, Sci. Rep., 2014, 4, 5619.

20 D. Rehana, A. K. Haleel and A. K. Rahiman, J. Chem. Sci., 2015, 127, 1155.

21 R. Ghosh, L. Pradhan, Y. P. Devi, S. S. Meena, R. Tewari, A. Kumar, S. Sharma, N. S. Gajbhiye, R. K. Vatsa, B. N. Pandey and R. S. Ningthoujam, J. Mater. Chem., 2011, 21, 13388.

22 R. G. López, M. G. Pineda, G. Hurtado, R. Díaz de León, S. Fernández, H. Saade and D. Bueno, Int. J. Mol. Sci., 2013, 14, 19636.

23 H. P. Yiu, M. A. Keane, Z. A. D. Lethbridge, M. R. Lees, A. J. El Haj and J. Dobson, Nanotechnology, 2008, 19, 255606.

24 J. Chen, H. Shen, X. Li, J. Ruan and W. Yuan, Chem. Pap., 2016, 70, 1642.

25 W. T. Herrera, J. A. R. Guivar, J. C. Gonzalez and E. M. Baggio-Saitovitch, 7th International Conference on nanomaterials - Research \& application, Proceedings NANOCON, TANGER Ltd, Ostrava, Czech Republic, 1st edn, 2015, pp. 511-519, ISBN 978-80-87294-63-5.

26 M. Bloemen, W. Brullot, T. T. Luong, N. Geukens, A. Gils and T. Verbiest, J. Nanopart. Res., 2012, 14, 1100.

27 N. Baccile, R. Noiville, L. Stievano and I. V. Bogaert, Phys. Chem. Chem. Phys., 2013, 15, 1606.

28 Y. Zhang, B. Wang, X. Meng, G. Sun and C. Gao, Ann. Biomed. Eng., 2011, 39, 414.
29 J. Y. Park, E. S. Choi, M. J. Baek and G. H. Lee, Mater. Lett., 2009, 63, 379.

30 A. E. Aliaga, C. Garrido, P. Leyton, G. F. Diaz, J. S. GomezJeria, T. Aguayo, E. Clavijo, M. M. Campos-Vallette and S. Sanchez-Cortes, Spectrochim. Acta, Part A, 2010, 76, 458.

31 D. Wilson and M. A. Langell, Appl. Surf. Sci., 2014, 303, 6.

32 Z. Wang, H. Zhu, X. Wang, F. Yang and X. Yang, Nanotechnology, 2009, 20, 465606.

33 J. B. Wu, Y. F. Lin, J. Wang, P. J. Chang, C. P. Tasi, C. C. Lu, H. T. Chiu and Y. W. Yang, Inorg. Chem., 2003, 42, 4516.

34 Y. Shan and L. Gao, Nanotechnology, 2005, 16, 625.

35 C. Chaneac, E. Tronc and J. P. Jolivet, J. Mater. Chem., 1996, 6, 1905.

36 X. T. H. Hsieh, K. S. Ho, X. Bi, Y. K. Han, Z. L. Chen, C. H. Hsu and Y. C. Chang, Eur. Polym. J., 2009, 45, 613.

37 M. Herlitschke, S. Disch, I. Sergueev, K. Schlage, E. Wetterskog, L. Bergström and R. P. Hermann, J. Phys.: Conf. Ser., 2016, 711, 012002.

38 G. M. da Costa, C. Blanco-Andujar, E. De Grave and Q. A. Pankhurst, J. Phys. Chem. B, 2014, 118, 11738.

39 J. A. R. Guivar, A. I. Martínez, A. O. Anaya, L. D. L. S. Valladares, L. L. Félix and A. B. Dominguez, Adv. Nanopart., 2014, 3, 114.

40 A. Demir, A. Baykal, H. Sözeri and R. Topkaya, Synth. Met., 2014, 187, 75 .

41 M. Thommes, K. Kaneko, A. V. Neimark, J. P. Olivier, F. Rodriguez-Reinoso, J. Rouquerol and K. S. W. Sing, Pure Appl. Chem., 2015, 87, 1051.

42 L. El Hammari, H. Merroun, T. Coradin, S. Cassaignon and A. Laghzizil, Mater. Chem. Phys., 2007, 104, 448.

43 S. Dragan and A. Fitch, J. Chem. Educ., 1998, 75, 1018.

44 Y. Takeuchi, T. Suzuki and H. Arai, J. Chem. Eng. Jpn., 1998, 21, 98.

45 G. Cao and Y. Wang, Nanostructures and Nanomaterials, Synthesis, properties and applications, (OWorld Scientific Publishing Co. Pte. Ltd, 2nd edn, 2004, ISBN: 978-9814322-50-8.

46 J. F. Liu, Z. S. Zhao and G. B. Jiang, Environ. Sci. Technol., 2008, 42, 6949.

47 M. Kumari, C. U. Pittman Jr and D. Mohan, J. Colloid Interface Sci., 2015, 442, 120.

48 J. Aguado, J. M. Arsuaga and A. Arencibia, Int. J. Environ. Technol. Manage., 2010, 12, 381.

49 Y. F. Shen, J. Tang, Z. H. Nie, Y. D. Wang, Y. Ren and L. Zuo, Sep. Purif. Technol., 2009, 68, 312. 